University of Louisville

ThinkIR: The University of Louisville's Institutional Repository

Electronic Theses and Dissertations

$8-2010$

\title{
Maximizing the efficiency of a speed rail for the preparation of alcoholic beverages.
}

Ashley S. Riley

University of Louisville

Follow this and additional works at: https://ir.library.louisville.edu/etd

\section{Recommended Citation}

Riley, Ashley S., "Maximizing the efficiency of a speed rail for the preparation of alcoholic beverages."

(2010). Electronic Theses and Dissertations. Paper 1209.

https://doi.org/10.18297/etd/1209

This Master's Thesis is brought to you for free and open access by ThinkIR: The University of Louisville's Institutional Repository. It has been accepted for inclusion in Electronic Theses and Dissertations by an authorized administrator of ThinkIR: The University of Louisville's Institutional Repository. This title appears here courtesy of the author, who has retained all other copyrights. For more information, please contact thinkir@louisville.edu. 


\title{
MAXIMIZING THE EFFICIENCY OF A SPEED RAIL FOR THE PREPARATION OF ALCOHOLIC BEVERAGES
}

\author{
By \\ Ashley S. Riley \\ B.S. Mathematics, Saint Mary-of-the-Woods College, 2009
}

\begin{abstract}
A Thesis
Submitted to the faculty of the

Graduate School of the University of Louisville

In Partial Fulfillment of the Requirements

For the Degree of
\end{abstract}

Master of Science
In
Industrial Engineering

Department of Industrial Engineering

J.B. Speed School of Engineering

University of Louisville

Louisville, KY

August 2010 

Copyright 2010 by Ashley Riley

All rights reserved 
MAXIMIZING THE EFFICIENCY OF A SPEED RAIL FOR THE PREPARATION OF ALCOHOLIC BEVERAGES

\author{
By \\ Ashley S. Riley \\ B.S. Mathematics, Saint Mary-of-the-Woods College, 2009
}

A Masters thesis approved on

July 16,2010

By the following Committee:

Dr. William E. Biles, P.E.

Dr. Gail W. DePuy, P.E.

Dr. C. Tim Hardın 


\section{ABSTRACT \\ MAXIMIZING THE EFFICIENCY OF A SPEED RAIL FOR THE PREPARATION OF ALCOHOLIC BEVERAGES Ashley Riley July 16, 2010}

Typically bartenders will arrange liquor bottles in a bar based on their own preferences. This research project describes an alternative way to arrange the bottles on the speed rail more efficiently. This will allow bartenders to make drinks quicker and easier. The objective of this study is to develop some sort of heuristic using block diagramming to make every speed rail more efficient.

For this project three different bars' speed rails were observed. The factors considered were the top 20 selling mixed drinks at each bar and their current speed rail setup. A generalized heuristic was used to evaluate the speed rail and make changes to try and increase its efficiency. A block diagram of each speed rail was made to keep track of the progress along the way.

Linear programming and a real life example were used in this project to show that block diagramming truly made these speed rails more efficient. In the real life example each of the top 20 selling drinks was made and timed using the existing speed rail layout and then timed again using the new proposed layout. A quadratic assignment problem from linear programming was used to show that the layouts found using block diagramming were good answers. 


\section{ACKNOWLEDGEMENTS}

This thesis discusses a very unique topic that has not been discussed or written about very much. The author wishes to thank Dr. William Biles and Dr. Aldo McLean for all of their help and support. The author also wishes to thank Dr. Gail DePuy and Dr. Tim Hardin for making time to serve on this thesis committee. The author also wishes to thank all of the owners and bartenders of the three establishments that are mentioned, without them this project would not have been possible. Lastly the author would like to thank Leslie Lee for drawing all of the figures on her computer. 


\section{TABLE OF CONTENTS}

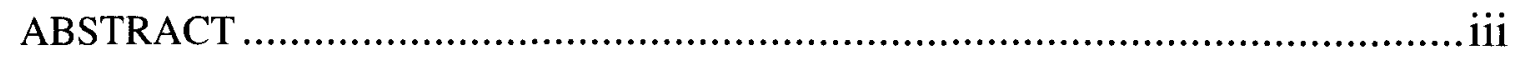

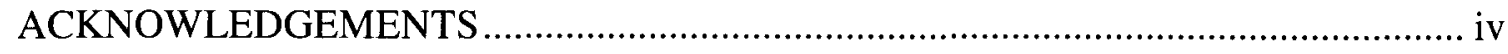

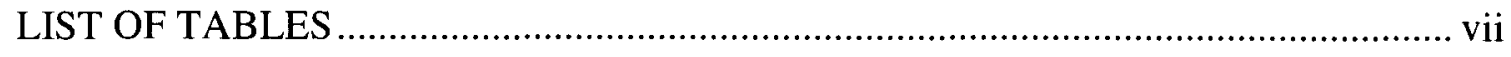

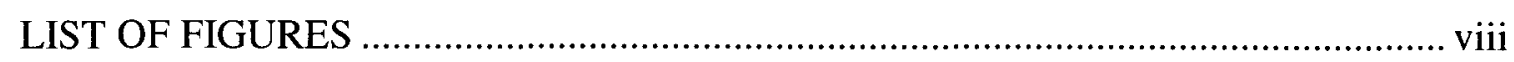

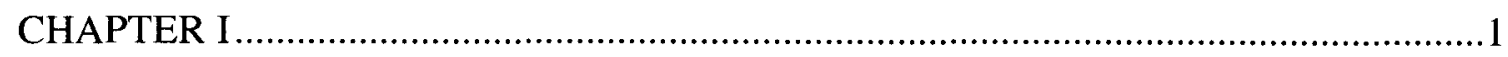

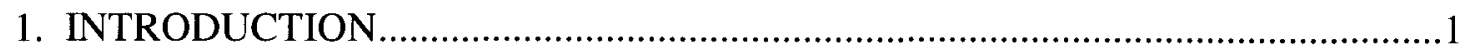

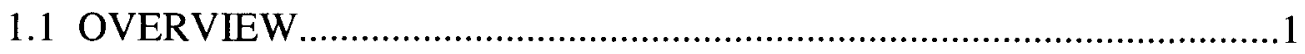

1.2 FUNDAMENTALS OF BLOCK DIAGRAMMING ..............................

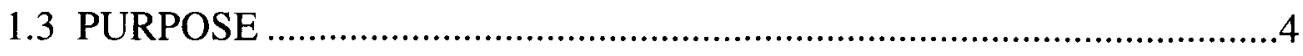

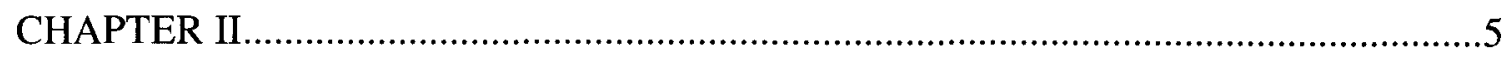

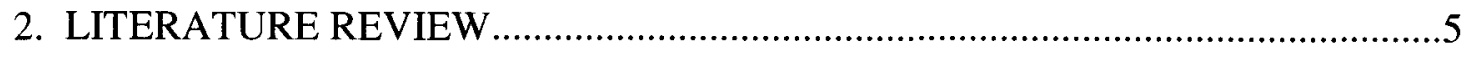

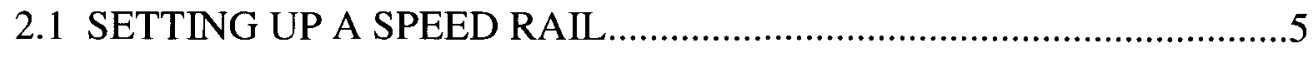

2.2 BLOCK DIAGRAMMING EXAMPLES .......................................

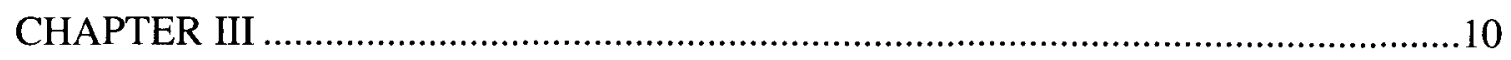

3. GENERALIZED HEURISTIC ................................................................ 10 
3.2 GENERALIZED HEURSITIC STEPS...............................................11

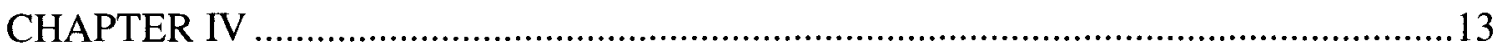

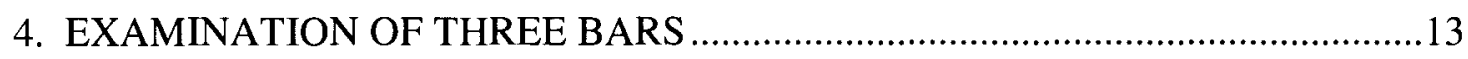

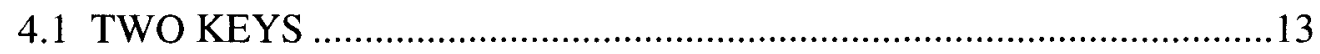

4.1.1 BAR SUMMARY ...............................................................13

4.1.2 TWO KEYS INFORMATION ..............................................13

4.1.3 SPECIALIZED HEURISTIC AND BLOCK DIAGRAMS ........15

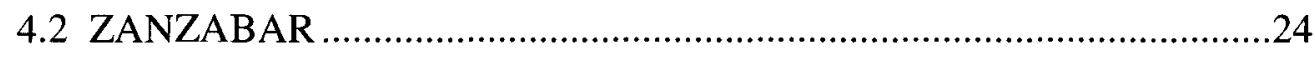

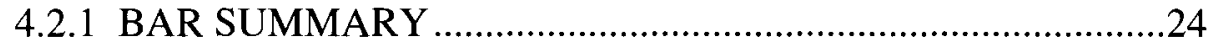

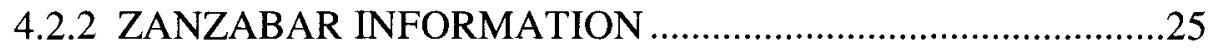

4.2.3 SPECIALIZED HEURISTIC AND BLOCK DIAGRAMS .......26

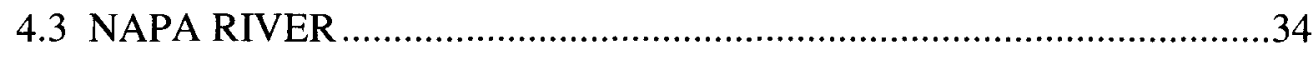

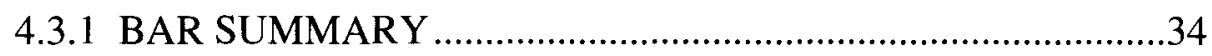

4.3.2 NAPA RIVER INFORMATION ……………….........................

4.3.3 SPECIALIZED HEURISTIC AND BLOCK DIAGRAMS ........36

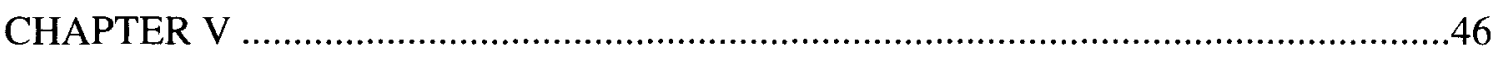

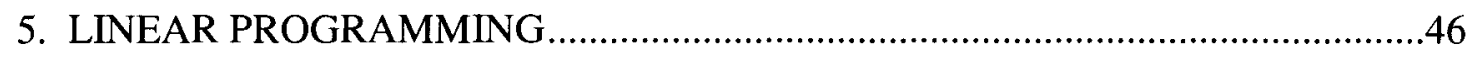

5.1 QUADRATIC ASSIGNMENT PROBLEM ............................................46

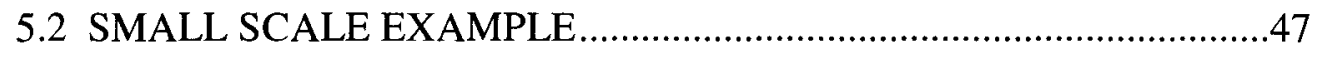


CHAPTER VI .52

6. REAL WORLD EXAMPLE. .52

CHAPTER VII .57

7. CONCLUSIONS, RECOMMENDATIONS, AND FUTURE RESEARCH .57

7.1 OVERVIEW .57

7.2 RECOMMENDATIONS FOR FUTURE RESEARCH .59

REFERENCES 61

APPENDIX A: FORMULATION FOR SMALL SCALE EXAMPLE IN LINGO ......62 FORMULATION FOR SMALL SCALE EXAMPLE .63

APPENDIX B: LINGO RESULTS FOR SMALL SCALE EXAMPLE ..... 64 LINGO FILE LARGE SCALE EXAMPLE IN LINGO .65 APPENDIX C: FORMULATION FOR TWO KEYS EXAMPLE IN

LINGO .70

FORMULATION FOR TWO KEYS EXAMPLE IN LINGO .71

APPENDIX D: LINGO RESULTS FOR TWO KEYS EXAMPLE. 73

LINGO RESULTS FOR TWO KEYS EXAMPLE .74

CURRICULUM VITA .87 


\section{LIST OF TABLES}

TABLE

PAGE

Table 4-1: Alcohols Needed to Make the Top 20 Selling Drinks for TwoKeys...........16

Table 4-2: Alcohols on the Current Speed Rail at Two Keys.......................... 17

Table 4-3: All Alcohol Bottles Involved in Block Diagrams for Two Keys...............18

Table 4-4: Top 20 Selling Drinks with Numbered Combinations for Two Keys.........20

Table 4-5: Alcohols Needed to Make the Top 20 Selling Drinks for Zanzabar...........27

Table 4-6: Alcohols on the Current Speed Rail at Zanzabar........................28

Table 4-7: All Alcohol Bottles Involved in Block Diagrams for Zanzabar...............29

Table 4-8: Top 20 Selling Drinks with Numbered Combinations for Zanzabar..........31

Table 4-9: Alcohols Needed to Make the Top 20 Selling Drinks for Napa River.........37

Table 4-10: Alcohols on the Current Speed Rail at Napa River........................ 38

Table 4-11: All Alcohol Bottles Involved in Block Diagrams for Napa River...........39

Table 4-12: Top 20 Selling Drinks with Numbered Combinations for Napa River.......41

Table 5-1: Numbered Alcohols for Small Scale Example..........................48

Table 5-2: Numbered Drink Combinations for Small Scale Example...................48

Table 6-1: Times to Make Top Drinks Using Existing Speed Rail Vs. Computed Speed

Rail................................................................... 54

Table 6-2: Example Times for One Round of Drinks for the Eight Tables...............55

Table 6-3: Example Calculations for the Total Time Saved............................56 


\section{LIST OF FIGURES}

FIGURE

PAGE

Figure 4-1: Current Speed Rail for Two Keys..................................22

Figure 4-2: Updated Speed Rail for Two Keys..................................23

Figure 4-3: Computed Speed Rail for Two Keys................................ 24

Figure 4-4: Current Speed Rail for Zanzabar................................. 32

Figure 4-5: Updated Speed Rail for Zanzabar....................................... 33

Figure 4-6: Computed Speed Rail for Zanzabar....................................34

Figure 4-7: Speed Rail for Napa River......................................43

Figure 4-8: Updated Speed Rail for Napa River...............................44

Figure 4-9: Computed Speed Rail for Napa River.............................45

Figure 5-1: Quadratic Assignment Problem Formulation.............................47

Figure 5-2: Initial Speed Rail for the Small Scale Example...........................49

Figure 5-3: Computed Speed Rail for the Small Scale Example.......................49

Figure 5-4: Computed Speed Rail for Two Keys Using Linear Programming............50

Figure 5-5: Computed Speed Rail for Two Keys Using Block Diagramming...........51 


\section{CHAPTER I}

\section{INTRODUCTION}

\subsection{OVERVIEW}

Every bar is different but the main goal of each establishment is the same, to make money. To make money a bar must satisfy the customer. This means that it must provide good service to the customer by getting them the correct drink and serving them quickly. The faster you help one customer the faster you can help another. Making the most money possible comes from serving the most drinks possible. On an average night this might not be a hard task for most establishments, but on a weekend or a holiday the bartenders can easily be overwhelmed by the amount of drinks they must make. For example, a bar with a capacity of 81 people might be filled to its limit on a holiday such as Mardi Gras. The bartender may have close to 40 customers in line to get a drink at one time. This is where every second counts so the layout of the speed rail becomes the most important thing.

Every bar has a different layout and this poses a potential problem for the bartender. Speed rails are put up where there is room and so the size of the speed rail depends on the layout of the bar. A speed rail is a grouping of bottles that are thought to be the most commonly used at the bar. Most speed rails are metal shelving units that hang under the bar close to an ice bin for easy access. However, speed rails may also 
consist of rows of bottles behind the bar up against a wall. Some speed rails hold 12 bottles, some hold 24 or more. Having little to no uniformity amongst the speed rails, bottle placement is not normally taken into consideration. Normally the major alcohols get a place in the speed rail and all other bottles are placed where the bartender can find room.

Bars and restaurants have their speed rails in place and filled but not according to how the drinks are made. For example, if three bottles are needed to make a particular top selling drink, all three bottles might be placed in the speed rail but not next to each other. This means it will take the bartender more time to search for each individual bottle rather than having them grouped together so all the bartender has to do is find the group and start pouring.

The bartender's top two jobs are to make the drinks correctly and to make them quickly. The goal of this study is to find a way to place the bottles on the speed rail so that they are quicker and easier to grab, therefore the drinks take less time to make. This would allow bartenders to serve drinks quicker and hopefully, because all the alcohols required to make the most popular drinks would be next to each other, the error rate would also go down.

Block diagramming is a good way to plan the layout of the bottles. It is very easy to draw and is a great visual aid because it is easy for everyone to understand. The objective of this study is to use block diagramming to create a generalized heuristic that will allow all different types of bars to make their speed rails more efficient. 


\subsection{FUNDAMENTALS OF BLOCK DIAGRAMMING}

The fundamentals of block diagramming are based on the idea of minimizing the nonadjacent movements in a process. A nonadjacent movement can be defined as a distance that is farther than one "block" away. For instance two steps in a process have to be either right next to each other or diagonal for them to be considered adjacent.

(Russell, R. S., and B.W. Taylor III. 2009)

There are three steps in block diagramming. The first is to assess the relationships each component has with one another in the process. This helps to determine which components need to be next to each other. Second, a chart needs to be created showing the two way movements between the related components. Lastly, different trials need to be run to determine which diagram minimizes the nonadjacent movements. (Russell, R. S., and B.W. Taylor III. 2009)

Block diagramming can be used to accomplish many different things. It can be used to determine where different machines should be placed in a factory to minimize the movement of the product. It can be used to show how power systems are laid out. It can even be used to determine an efficient layout for bottles on a speed rail. (Russell, R. S., and B.W. Taylor III. 2009)

The value of block diagramming is that it is very visual and easy to understand no matter what educational background one might have. It is a simple effective process that everyone can understand. 


\subsection{PURPOSE}

The goal of this study is to create a generalized heuristic using block diagramming so that no matter what the layout is or what the top 20 selling drinks are a restaurant can create an efficient speed rail layout. Although this idea seems simple, there is little to no information to draw from concerning this topic. Through the use of multiple examples this study examines the effectiveness of using block diagramming that could not otherwise be found in pre-existing literature. This study is attempting to find a more efficient way to place the alcohol bottles in a speed rail by minimizing the nonadjacent moves between bottles. 


\section{CHAPTER II}

\section{LITERATURE REVIEW}

\subsection{SETTING UP A SPEED RAIL}

The idea for writing this report didn't come from reading journal articles and observing a need for a change, it came from viewing so many different speed rails which all seemed to be inefficient. It looked as though every bar and restaurant had a different speed rail/layout for their alcohol bottles. All of these layouts seemed to be determined by one person, either the bartender that was currently working or the owner or bartender who set up the bar. There seemed to be some similar aspects but none of them seemed to be efficient. For example, every bar that was assessed in this report had the major alcohol bottles such as Vodka, Tequila, and Rum on their speed rail right next to each other along with the other major alcohols. However, there were no mixers, such as triple sec or schnapps, and no flavored alcohols anywhere near the major alcohols. This poses a problem for almost any drink that is not just a hard alcohol and soda or tonic water because other mixers and/or flavored alcohols are needed to make almost all the other drinks. This means the bartender has to search for the other bottles. The entire thought process seemed appropriate at a first glance but once a deeper look was taken it was very

inefficient. A literature review was conducted to get a better idea on how bars set up their speed rails. 
This research project is unique in that it has very little information available to draw from. When searching either online or in journal articles, there is hardly any information on where to place your alcohol bottles in your speed rail. There are articles that tell you things such as, "In a high-volume or service bar, frequently poured liquor should be located in front of the bartender" (http://findarticles.com/p/articles/mi_m3190/is_21_32/ai_50093121/). Although this report shows this piece of information to be true, it is very vague and doesn't give any sort of advice as to how these frequently used liquors should be placed in relation to one another. This advice doesn't help the study.

Instead of focusing on the main points of an abundance of information, this literature review focused on the lack of information available. When searching for information on how to set up a brand new bar, the advice given is very broad. "Wells, which allow frequently used liquors and liqueurs to be easily accessed, are a necessity in public bars" (McDonald, A. 2010). This is good advice but to be useful it needs to be much more detailed. It brings up things that need to be defined in order for this idea to be implemented. What is a frequently used liquor/liqueur? Does easily accessed just mean the bottle is not in storage? Without these answers the advice is useless.

Who determines the arrangement of the bottles on the speed rail? It depends on the bar; each bar is different. At all three bars and restaurants that were observed in this report, the person who set up the speed rail was the very first bartender each of the establishments had. One of the many jobs a bartender has is to familiarize themselves with the alcohol bottles and according to some sources they should also set up the speed rail to their liking. "Arranging liquors and drinks in a particular way" 
(http://www.targetwoman.com/articles/bartending-job.html). Again the information that is available is so vague and ill-defined that it is useless.

\subsection{BLOCK DIAGRAMMING EXAMPLES}

Block Diagramming is widely used in the engineering world for many different purposes. It has been used to model commercial and industrial power systems, digital signal processing systems (DSP), and even chemical processes. The visual aspect of block diagrams is what makes them so useful. "Visual information is the clearest way to present material and is least likely to be misinterpreted," (Shaeiwitz, Joseph A. et al. 2009). This report used block diagramming because it helped to easily show the relationships between bottles, but that is not all it can do.

Industrial and commercial power systems use block diagramming because it is easily understood by a majority of people. The engineers who design them, the managers who run them, and the people whose job it is to sell them can all understand a block diagram. The diagram shows connections. "It is a graphical presentation of a system diagram in reliability-wise or functional logic; i.e., connecting subsystems or components according to their function or reliability relationship" (Wang, W. et al. 2004). This idea of showing a connection between the important components of a system is shown in this report through block diagramming.

Power systems use block diagrams to represent more than just one combination.

They are used to show much more. "RBDs are based on system design, operation and maintenance procedures, and analysis of component failure effects" (Wang, W. et al. 
2004). This design of using block diagramming to show much more than just one connection might be something to consider adding to this report in the future.

Digital signal processing systems (DSP) have been using block diagrams for decades. "These tools help engineers manage complicated designs by representing a system's functions expressively and compactly" (http://www.bdti.com/articles/info_dspmt95blockdiagram.htm). This idea of using block diagrams to represent a system in a compact way is shown in the research study. Bars have many different types of alcohols and it would be overwhelming and confusing to try and study all of their relationships with one another. That is another reason the study used block diagramming, to keep things compact.

Similar to this study, DSP system block diagrams can be drawn on computers. However, they can be used to provide support in other areas such as simulation, hardware synthesis, and search and optimization of system characteristics. Again, being able to use the block diagrams formulated in this study in other areas such as simulation should be addressed in future research.

The chemical process industry (CPI) deals with many different products that when combined can be extremely dangerous. Therefore it is vital that they have some sort of way to present these combinations so they will not be misinterpreted. This is done through block flow diagrams. These diagrams are very similar to block diagrams in that they have blocks to represent components in the system and connections to represent important relationships such as input and output streams. Most bars have multiple bartenders and they all use the same speed rail. It is important that they all can understand the combinations needed to make a particular drink. However, it is not as 
vital that a customer receive the exact drink as it is that a chemical engineer combines the correct chemicals. (Shaeiwitz, Joseph A. et al. 2009)

Even more helpful to chemical engineers are process flow diagrams (PFD). "The PFD contains the bulk of the chemical engineering data necessary for the design of a chemical process" (Shaeiwitz, Joseph A. et al. 2009). PFD's contain all the necessary equipment with a specific name and number, process flow streams and their descriptions, utility streams related to the necessary equipment, and basic control loops. This is much more detailed than the block diagrams presented in this research study. Future research studies may want to try and mimic this PFD approach and add in all the other parts needed to make these top 20 selling drinks.

Block diagrams are used for many reasons in many different areas of engineering. They can be helpful visual aids that can be understood by everyone and can be hard to misread so as to avert big explosions. Block diagrams can help to show only certain steps in a process so that it is compact and again easy to understand. This study used block diagrams for all of these reasons. Having a visual representation of the speed rail and the alcohol bottles on it with lines representing the connections between the bottles makes it very easy to see how effective changes can be. 


\section{CHAPTER III}

\section{GENERALIZED HEURISTIC}

\subsection{BACKGROUND INFORMATION}

The generalized heuristic was created using the three steps of block diagramming.

First, the study needed to define its components. Because each bar carries different types of alcohol, the study had to decide which alcohols were the most important. This report focused on the different alcohols that made up the top 20 selling mixed drinks at each establishment. Only the top 20 drinks were taken into consideration because that seemed to be a decent number of alcohol bottles to place on the speed rail. If more drinks were accounted for there would not be room on the speed rail to put the alcohols needed to make these drinks. Second, each drink was broken down into the individual alcohol bottles so that the relationships between the bottles could be examined. Lists were made of all the combination drinks. Lastly, different diagrams were drawn to try and minimize the number of nonadjacent movements between the bottles.

There are three diagrams for each of the bars that were observed. The first diagram is of the current speed rail at each establishment. The second diagram shows the all of the bottles needed to make the top 20 selling drinks on the speed rail but not in any particular order. The third diagram is the computed diagram using the generalized heuristic. This diagram is the most efficient layout the study could find using the heuristic. However, it may not be the only efficient layout for the given bottles. 


\subsection{GENERALIZED HEURISTIC STEPS}

Below is the step by step heuristic procedure on how to arrive at the new bottle arrangements for each of the bars looked at.

1) Get a list of the top 20 mixed drinks sold and their ingredients. Using this information make a list of all the bottles needed to make these top 20 drinks. (list \#1 numbering the bottles $1,2, \ldots, n)$

2) Write down the current speed rail layout.

3) Write down what bottles are currently on the speed rail. (list \#2)

4) Compare the bottles in list \#1 with the bottles in list \#2. Add the bottles that aren't in list \#1 but are in list \#2 to the end of list \#1. (This will be list \#3 numbering the bottles $1,2, \ldots, \mathrm{n}, \mathrm{n}+1, \ldots)$

5) Draw a block diagram of the existing speed rail. All bottles that are needed but that aren't currently on the speed rail are automatically counted as a nonadjacent movement. (Use list \#3 to show where the different alcohols are located)

6) Compare and contrast list \#1 with list \#2. All of the bottles that were in list \#2 but not in list \#1 are taking up valued space and should be removed from the rail.

7) Place the bottles in the new block diagram according to their numbers from list $\# 1$. (i.e. $1,2, \ldots, n)$

8) Look at the list of drinks and separate out all the bottles that can stand alone or that have only a single connection. Total up how many bottles this is and try to place them on their own rail away from all the multiple combination drinks. 
9) Now determine which bottles are parts of multiple drink combinations and list the bottles with combinations over two.

10) List out the combinations which were successful ( i.e. only adjacent moves were made) and which combinations were unsuccessful. (i.e. combinations with nonadjacent moves) 


\section{CHAPTER IV}

\section{EXAMINATION OF THREE BARS}

\subsection{TWO KEYS}

\subsubsection{BAR SUMMARY}

Two Keys is a small bar and grill that just opened two years ago. It is owned by a husband and wife and has a very small staff. The total occupancy of the bar is only 81 people inside and countless number of people outside on the patio. The layout of the bar makes it a struggle to have more than one bartender behind the bar at any one time. Therefore, one bartender, one server, one cook, and one manager work at once. At this establishment the bartender is required to not only make drinks for the entire place but also to wash the cups and glasses, to take food orders for the people sitting at the bar, and to carry on conversations with the customers. This is a stretch for one person when the bar is very full. The owners and the first bartender set up the speed rail by placing all the hard alcohols that were used the most often on the speed rail. They then added in other bottles as they saw fit, basically trial and error.

\subsubsection{TWO KEYS INFORMATION}

Two Key's top 20 mixed drinks are as follows: Cherry Bomb (Cherry vodka and Red Bull), Grape Bomb (Grape vodka and Red Bull), Captain and Coke, Jack Daniels 
and Pepsi, Rum and Pepsi, Vodka Tonic, BJ Shot (Baileys and Kahlua), Lemon

Drop (Absolut Citron, Triple Sec, and Sweet n Sour), Margarita (Tequila, Triple Sec,

Sweet n Sour, and Roses Lime), Parrot Bay and Pineapple, Seven and Seven (Seagram's

Seven and Sprite), Jim Beam and Pepsi, Vodka Cranberry, Raspberry vodka and Sprite,

Vodka and Red Bull, Vodka Martini (Vodka and Dry Vermouth), Ice Pick (Vodka and

Tea), Long Island (Vodka, Rum, Gin, Triple Sec, and Sweet n Sour), Peach Martini

(Peach Vodka, Peach Schnapps, and Sweet n Sour), and Sex on the Beach (Vodka, Peach

Schnapps, and Raspberry Schnapps).

There are 24 spaces on the current speed rail with only 23 spaces being occupied.

The bottles in those 23 spaces are as follows: Vodka, Rum, Gin, Tequila, Triple Sec,

Bourbon, Jack Daniels, Captain Morgan, Absolut Vodka, Amaretto, Roses Lime,

Grenadine, Sweet n Sour, Absolut Citron, Kahlua, Smirnoff Vanilla Vodka, Smirnoff

Blueberry Vodka, Apple Sour Pucker, Peach Schnapps, Buttershots Schnapps, Raspberry

Schnapps, Pomegranate Schnapps, and Melon Schnapps.

The 22 bottles needed to make all of the top 20 mixed drinks are as follows:

Vodka, Rum, Gin, Tequila, Triple Sec, Jack Daniels, Captain Morgan, Roses Lime,

Sweet n Sour, Absolut Citron, Kahlua, Peach Schnapps, Raspberry Schnapps, Cherry

Vodka, Grape Vodka, Baileys, Parrot Bay, Seagram's 7, Jim Beam, Raspberry Vodka,

Dry Vermouth, and Peach Vodka. 


\subsubsection{SPECIALIZED HEURISTIC AND BLOCK DIAGRAMS}

Each of the bars required a slightly altered version of the generic heuristic to maximize the number of adjacent moves, listed below is the specialized heuristic for Two Keys.

1) Get a list of the top 20 mixed drinks sold and their ingredients. Using this information make a list of all the bottles needed to make these top 20 drinks. (list \#1 numbering the bottles $1,2, \ldots, n)$ 
Table 4-1: Alcohols Needed to Make the Top 20 Selling Drinks for Two Keys

\begin{tabular}{|r|l|}
\hline $\begin{array}{l}\text { Bottle } \\
\text { Number }\end{array}$ & Alcohol \\
\hline 1 & Cherry Vodka \\
\hline 2 & Grape Vodka \\
\hline 3 & Captain Morgan \\
\hline 4 & Jack Daniels \\
\hline 5 & Rum \\
\hline 6 & Vodka \\
\hline 7 & Baileys \\
\hline 8 & Kahlua \\
\hline 9 & Absolut Citron \\
\hline 10 & Triple Sec \\
\hline 11 & Sweet n Sour \\
\hline 12 & Tequila \\
\hline 13 & Roses Lime \\
\hline 14 & Parrot Bay \\
\hline 15 & Seagram's 7 \\
\hline 16 & Jim Beam \\
\hline 17 & Raspberry Vodka \\
\hline 18 & Dry Vermouth \\
\hline 19 & Gin \\
\hline 20 & Peach Vodka \\
\hline 21 & Peach Schnapps \\
\hline 22 & Raspberry \\
Schnapps \\
\hline & \\
\hline & \\
\hline & \\
\hline & \\
\hline &
\end{tabular}

2) Write down the current speed rail layout.

a. 12 bottles on the front speed rail - six on top and 6 on bottom.

b. 12 bottles on the side speed rail - six on the right and six on the left.

3) Write down what bottles are currently on the speed rail. (list \#2) 
Table 4-2: Alcohols on the Current Speed Rail at Two Keys

\begin{tabular}{|r|l|}
\hline $\begin{array}{l}\text { Bottle } \\
\text { Number }\end{array}$ & Alcohol \\
\hline 1 & Vodka \\
\hline 2 & Rum \\
\hline 3 & Gin \\
\hline 4 & Tequila \\
\hline 5 & Triple Sec \\
\hline 6 & Bourbon \\
\hline 7 & Jack Daniels \\
\hline 8 & Captain Morgan \\
\hline 9 & Absolut Vodka \\
\hline 10 & Amaretto \\
\hline 11 & Roses Lime \\
\hline 12 & Grenadine \\
\hline 13 & Sweet n Sour \\
\hline 14 & Absolut Citron \\
\hline 15 & Kahlua \\
\hline 16 & Smirnoff Vanilla Vodka \\
\hline 17 & Smirnoff Blueberry \\
\hline 18 & Apdka Sour Pucker \\
\hline 19 & Peach Schnapps \\
\hline 20 & Buttershots Schnapps \\
\hline 21 & Raspberry Schnapps \\
\hline 22 & Pomegranate Schnapps \\
\hline 23 & Melon Schnapps \\
\hline & \\
\hline
\end{tabular}

4) Compare the bottles in list \#1 with the bottles in list \#2. Add the bottles that aren't in list \#1 but are in list \#2 to the end of list \#1. (This will be list \#3 numbering the bottles $1,2, \ldots, \mathrm{n}, \mathrm{n}+1, \ldots)$ 
Table 4-3: All Alcohol Bottles Involved in Block Diagrams for Two Keys

\begin{tabular}{|r|l|}
\hline $\begin{array}{r}\text { Bottle } \\
\text { Number }\end{array}$ & Alcohol \\
\hline 1 & Cherry Vodka \\
\hline 2 & Grape Vodka \\
\hline 3 & Captain Morgan \\
\hline 4 & Jack Daniels \\
\hline 5 & Rum \\
\hline 6 & Vodka \\
\hline 7 & Baileys \\
\hline 8 & Kahlua \\
\hline 9 & Absolut Citron \\
\hline 10 & Triple Sec \\
\hline 11 & Sweet n Sour \\
\hline 12 & Tequila \\
\hline 13 & Roses Lime \\
\hline 14 & Parrot Bay \\
\hline 15 & Seagram's 7 \\
\hline 16 & Jim Beam \\
\hline 17 & Raspberry Vodka \\
\hline 18 & Dry Vermouth \\
\hline 19 & Gin \\
\hline 20 & Peach Vodka \\
\hline 21 & Peach Schnapps \\
\hline 22 & Raspberry Schnapps \\
\hline 23 & Bourbon \\
\hline 24 & Absolut Vodka \\
\hline 25 & Amaretto \\
\hline 26 & Grenadine \\
\hline 27 & Smirnoff Vanilla Vodka \\
\hline 28 & Smirnoff Blueberry \\
\hline 29 & Apple Sour Pucker \\
\hline 30 & Buttershots Schnapps \\
\hline 31 & Pomegranate Schnapps \\
\hline 32 & Melon Schnapps \\
\hline & \\
\hline
\end{tabular}


5) Draw a block diagram of the existing speed rail. All bottles that are needed but that aren't currently on the speed rail are automatically counted as a nonadjacent movement. (Use list \#3 to show where the different alcohols are located)

6) Compare and contrast list \#1 with list \#2. All of the bottles that were in list \#2 but not in list $\# 1$ are taking up valued space and should be removed from the rail.

7) Place the bottles in the new block diagram according to their numbers from list \#1 (i.e. $1,2, \ldots, n)$

a. There are 22 bottles needed to make up the top 20 mixed drinks.

8) (This is where the heuristic becomes specialized) Look at the list of drinks and separate out all the bottles that can stand alone or that have only a single connection. Total up how many bottles this is and try to place them on their own rail away from all the multiple combination drinks.

a. There are eight bottles that stand alone and two bottles that share a single connection, this is 10 bottles total.

b. There are 24 total spaces on the speed rail but only 22 bottles needed, therefore we can put the 10 bottles found on the side speed rail in order of their importance. (i.e. according to what drink number they made up in the top 20 mixed drinks list)

9) Now determine which bottles are parts of multiple drink combinations and list the bottles with combinations over two.

a. Bottle 10 is in combinations with four other bottles: $9,11,12$, and 19 .

b. Bottle 21 is in combination with four other bottles: $6,11,20$, and 22 .

c. Bottle 6 is in combination with three other bottles: 5,18 , and 21 . 
d. Bottle 11 is in combination with three other bottles: 10, 13, and 21 .

Table 4-4: Top 20 Selling Drinks with Numbered Combinations for Two Keys

\begin{tabular}{|l|l|l|}
\hline Top 20 Selling Drinks & Ingredients & $\begin{array}{l}\text { Number } \\
\text { Combinations }\end{array}$ \\
\hline Cherry Bomb & Cherry Vodka and Red Bull & \\
\hline Grape Bomb & Grape Vodka and Red Bull & \\
\hline Captain and Coke & Captain and Coke & \\
\hline Jack Daniels and Pepsi & Jack Daniels and Pepsi & \\
\hline Rum and Pepsi & Rum and Pepsi & \\
\hline Vodka Tonic & Vodka and Tonic & 7,8 \\
\hline BJ Shot & Baileys and Kahlua & $9,10,11$ \\
\hline Lemon Drop & Absolut Citron, Triple Sec, and Sweet n Sour & $12,10,11,13$ \\
\hline Margarita & $\begin{array}{l}\text { Tequila, Triple Sec, Sweet n Sour, and Roses } \\
\text { Lime }\end{array}$ & \\
\hline Parrot Bay and Pineapple & Parrot Bay and Pineapple & \\
\hline Seven and Seven & Seagram's 7 and Sprite & $6,21,22$ \\
\hline Jim Beam and Pepsi & Jim Beam and Pepsi & $6,18,10,11$ \\
\hline Vodka Cranberry & Vodka and Cranberry & \\
\hline $\begin{array}{l}\text { Raspberry Vodka and } \\
\text { Sprite }\end{array}$ & Raspberry Vodka and Sprite & \\
\hline Vodka and Red Bull & Vodka and Red Bull & \\
\hline Vodka Martini & Vodka and Dry Vermouth & \\
\hline Ice Pick & Vodka and Ice Tea & \begin{tabular}{l} 
\\
\hline Long Island
\end{tabular} \\
\hline Peach Martini & $\begin{array}{l}\text { Podka, Rum, Gin, Triple Sec, and Sweet } n \\
\text { Sour }\end{array}$ & \\
\hline Sex on the Beach & Sodka, Peach Schnapps, and Raspberry & \\
\hline
\end{tabular}

10) List out the combinations which were successful (i.e. only adjacent moves were made) and which combinations were unsuccessful. (i.e. combinations with nonadjacent moves)

a. Combination 7-8 was successful. (in step 8)

b. Combination 9-10-11 was successful. 

c. Combination 12-10-11-13 was successful.
d. Combination 6-18 was successful.
e. Combination 6-5-19-10-11 was successful.
f. Combination 6-21-22 was successful.
g. Combination 20-21-11 was unsuccessful.

The current speed rail for Two Keys is shown in Figure 4-1. From looking at the figure it can be seen that the current setup is very inefficient with four adjacent moves and nine nonadjacent moves. 


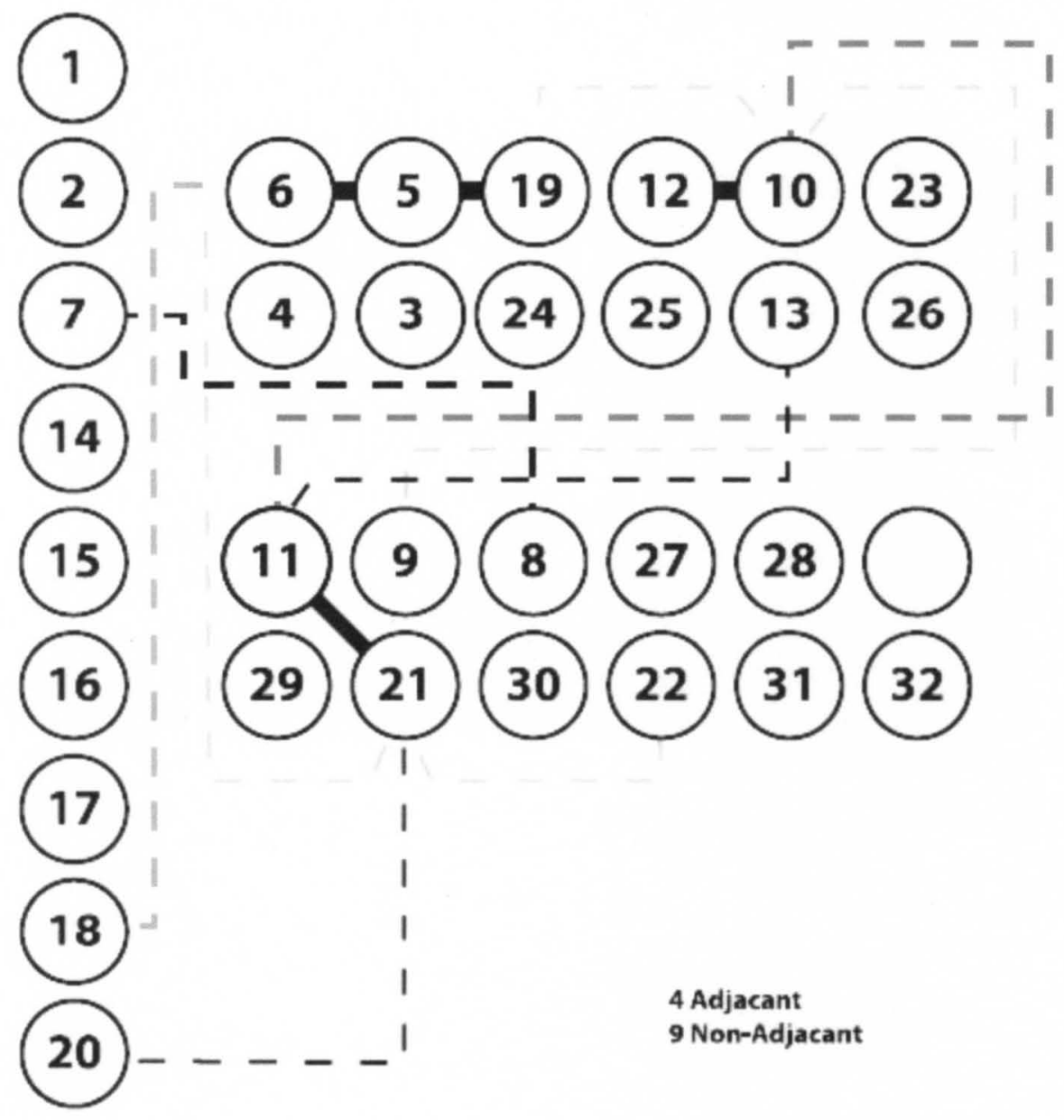

Figure 4-1: Current Speed Rail for Two Keys

In step seven of the heuristic the newly listed bottles are placed into the block diagram; this can be seen in Figure 4-2. By just using the bottles needed to make the top 20 mixed drinks and adding those into the block diagram the group increased the adjacent moves by one, totaling five adjacent moves to eight nonadjacent moves. This shows that the heuristic is on the right path. 


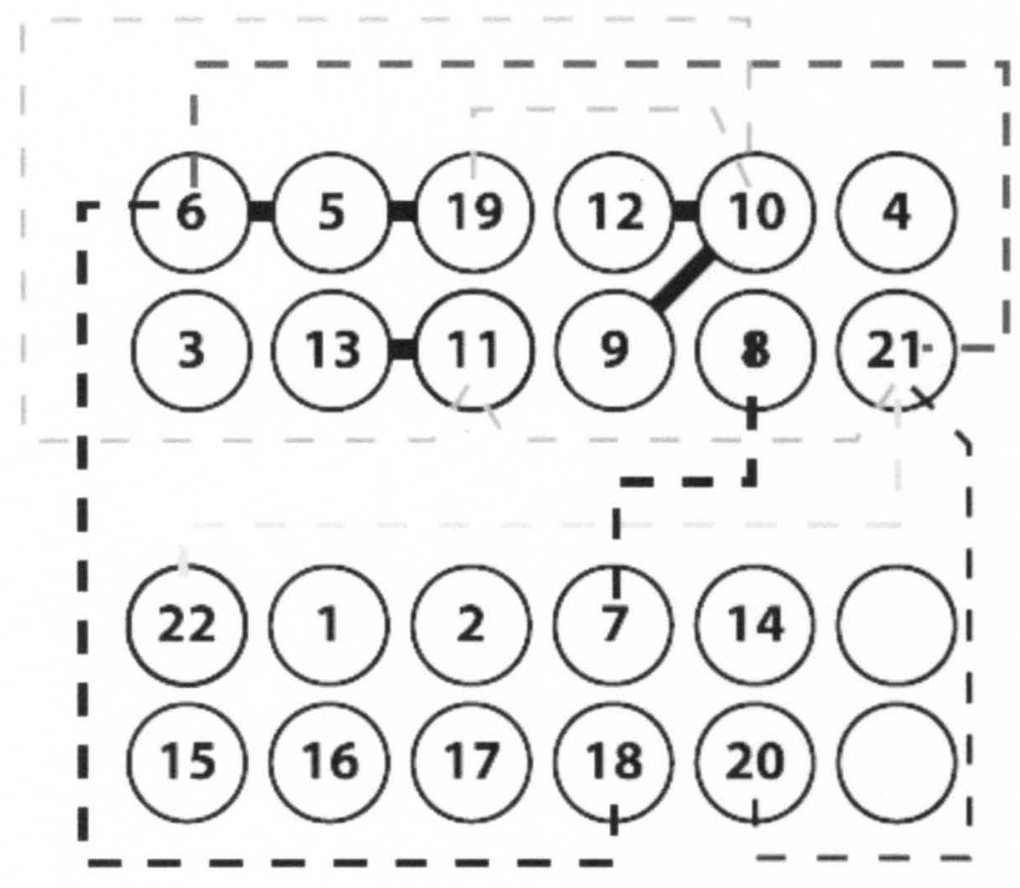

5 Adjacant 8 Non-Adjacant

Figure 4-2: Updated Speed Rail for Two Keys

Using the heuristic the study was able to compute an efficient speed rail. Figure 4-3 shows the computed speed rail with 12 adjacent moves and only one nonadjacent move. 

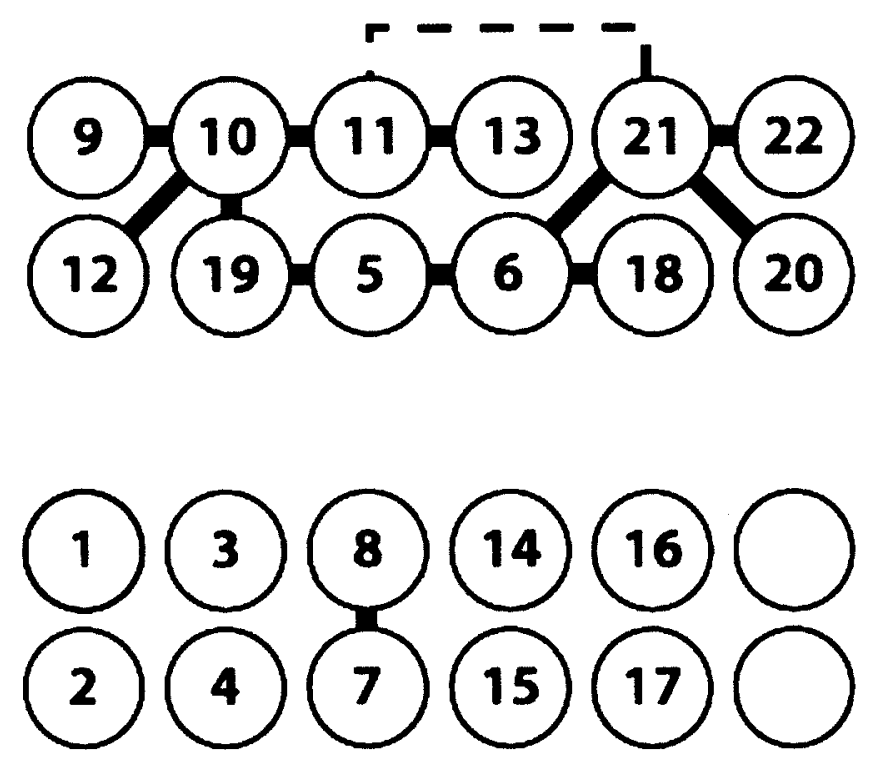

12 Adjacant

1 Non-Adjacant

\section{Figure 4-3: Computed Speed Rail for Two Keys}

The current speed rail for Two Keys was found to be very inefficient. Once the heuristic was applied the number of adjacent moves tripled and the ending number of nonadjacent moves was one. The research study took this speed rail from having four adjacent moves to 12 adjacent moves. This is a big improvement.

\subsection{ZANZABAR}

\subsubsection{BAR SUMMARY}

Zanzabar is a medium-sized bar and grill. They are located very close to the University of Louisville and are therefore very busy on the weekends and during the 
lunch hours. This establishment has been known to have more than 300 customers inside the bar at one time. This presents a lot of sales and drinks to be made for the three bartenders that are scheduled to work on weekend nights. There is one single speed rail that is full all the time and holds only the major alcohols. They have set aside two other speed rails which they fill up differently every day. For example, if a customer sits down and starts ordering Long Islands then the bartender moves the Dekuyper LIT bottle to one of the two open speed rails. This continues until all the spaces are full. Once a customer leaves, that bottle they were using might be placed back in storage and a new one might take its place. The study saw this as problematic because the bottles needed to make the top 20 mixed drinks were not anywhere near the bartenders initially. This is a waste of time to go get them.

\subsubsection{ZANZABAR INFORMATION}

Zanzabar's top 20 mixed drinks are as follows: Bloody Mary (Vodka and Zing Zang mix), Long Island Ice Tea ( Dekuyper Bottle), Bourbon and Coke, Vodka Cranberry, Screwdriver (Vodka and OJ), Amaretto Sour, Margarita (Tequila, Triple Sec, Sweet and Sour, Lime Juice), Sex on the Beach (Vodka, Peach Schnapps, OJ, Cranberry, Pineapple), Tequila Sunrise (Tequila, OJ, and Grenadine), Whiskey Sour, White Russian (Vodka, Kahlua, Cream), Apple Tini (Citrus Vodka, Apple Pucker, Melon Schnapps, Sweet n Sour), Manhattan (Whiskey, Sweet Vermouth, Grenadine), Tom Collins (Gin, Lemon Juice, Sugar, Club soda), Cosmo (Citrus Vodka, Cranberry, Grand Marnier, Lime Juice), Fuzzy Navel (Peach Schnapps and OJ), Black Russian (Vodka and Kahlua), Mai 
Tai (Rum, Malibu, OJ, Grenadine, and Pineapple), Sea Breeze (Vodka, pineapple, and grapefruit), and Vodka Tonic.

There are currently three speed rails at Zanzabar but only the six spot speed rail is

full. As customers order drinks the other two speed rails are filled up. The six spot speed rail consists of Early Times, Vodka, Gin, Rum, Scotch, and Tequila.

The 20 bottles needed to make all of the top 20 mixed drinks are as follows:

Vodka, Dekuyper Long Island Ice Tea, Bourbon, Amaretto, Tequila, Triple Sec, Sweet n

Sour, Peach Schnapps, Grenadine, Whiskey, Kahlua, Citrus Vodka, Apple Pucker, Melon

Schnapps, Sweet Vermouth, Gin, Grand Marnier, Lime Juice, Rum, and Malibu.

\subsubsection{SPECIALIZED HEURISTIC AND BLOCK DIAGRAMS}

Each of the bars required a slightly altered version of the generic heuristic to maximize the number of adjacent moves, listed below is the specialized heuristic for Zanzabar.

1) Get a list of the top 20 mixed drinks sold and their ingredients. Using this information make a list of all the bottles needed to make these top 20 drinks. (list \#1 numbering the bottles $1,2, \ldots, \mathrm{n})$ 
Table 4-5: Alcohols Needed to Make the Top 20 Selling Drinks for Zanzabar

\begin{tabular}{|r|l|}
\hline $\begin{array}{l}\text { Bottle } \\
\text { Number }\end{array}$ & Alcohol \\
\hline 1 & Vodka \\
\hline 2 & Tekuyper Long Island Ice \\
\hline 3 & Bourbon \\
\hline 4 & Amaretto \\
\hline 5 & Tequila \\
\hline 6 & Triple Sec \\
\hline 7 & Sweet n Sour \\
\hline 8 & Peach Schnapps \\
\hline 9 & Grenadine \\
\hline 10 & Early Times \\
\hline 11 & Kahlua \\
\hline 12 & Citrus Vodka \\
\hline 13 & Apple Pucker \\
\hline 14 & Melon Schnapps \\
\hline 15 & Sweet Vermouth \\
\hline 16 & Gin \\
\hline 17 & Grand Marnier \\
\hline 18 & Lime Juice \\
\hline 19 & Rum \\
\hline 20 & Malibu \\
\hline & \\
\hline
\end{tabular}

2) Write down the current speed rail layout.

a. Six bottles on the single speed rail.

b. Eight bottles on the side speed rail - four on the right and four on the left.

c. Six bottles on the other side speed rail- three on the right and three on the left.

3) Write down what bottles are currently on the speed rail. (list \#2) 
Table 4-6: Alcohols on the Current Speed Rail at Zanzabar

\begin{tabular}{|r|l|}
\hline $\begin{array}{l}\text { Bottle } \\
\text { Number }\end{array}$ & Alcohol \\
\hline & Early \\
1 & Times \\
\hline 2 & Vodka \\
\hline 3 & Gin \\
\hline 4 & Rum \\
\hline 5 & Scotch \\
\hline 6 & Tequila \\
\hline
\end{tabular}

4) Compare the bottles in list \#1 with the bottles in list \#2. Add the bottles that aren't in list \#1 but are in list \#2 to the end of list \#1. (This will be list \#3 numbering the bottles $1,2, \ldots, n, n+1, \ldots)$ 
Table 4-7: All Alcohol Bottles Involved in Block Diagrams for Zanzabar

\begin{tabular}{|l|l|}
\hline $\begin{array}{l}\text { Bottle } \\
\text { Number }\end{array}$ & Alcohol \\
\hline 1 & Vodka \\
\hline 2 & Tea \\
\hline 3 & Bourbon \\
\hline 4 & Amaretto \\
\hline 5 & Tequila \\
\hline 6 & Triple Sec \\
\hline 7 & Sweet n Sour \\
\hline 8 & Peach Schnapps \\
\hline 9 & Grenadine \\
\hline 10 & Early Times \\
\hline 11 & Kahlua \\
\hline 12 & Citrus Vodka \\
\hline 13 & Apple Pucker \\
\hline 14 & Melon Schnapps \\
\hline 15 & Sweet Vermouth \\
\hline 16 & Gin \\
\hline 17 & Grand Marnier \\
\hline 18 & Lime Juice \\
\hline 19 & Rum \\
\hline 20 & Malibu \\
\hline 21 & Scotch \\
\hline & \\
\hline & \\
\hline & \\
\hline & \\
\hline &
\end{tabular}

5) Draw a block diagram of the existing speed rail. All bottles that are needed but that aren't currently on the speed rail are automatically counted as a nonadjacent movement. (Use list \#3 to show where the different alcohols are located)

6) Compare and contrast list \#1 with list \#2. All of the bottles that were in list \#2 but not in list \#1 are taking up valued space and should be removed from the rail.

7) Place the bottles in the new block diagram according to their numbers from list \#1 (i.e. $1,2, \ldots, \mathrm{n})$

a. There are 20 bottles needed to make up the top 20 mixed drinks. 
8) (This is where the heuristic becomes specialized) Look at the list of drinks and separate out all the bottles that can stand alone or that have only a single connection. Total up how many bottles this is and try to place them on their own rail away from all the multiple combination drinks.

a. There are three bottles that stand alone and no bottles that share a single connection, this is three bottles total.

b. There are 20 total spaces on the speed rail and 20 bottles needed, we can put some of the three bottles found on the single speed rail.

9) Now determine which bottles are parts of multiple drink combinations and list the bottles with combinations over two.

a. Bottle 7 is in combinations with five other bottles: $4,6,10,14$, and 18 .

b. Bottle 9 is in combination with three other bottles: 5,15 , and 20 .

c. Bottle 18 is in combination with three other bottles: 7,12 , and 17 . 
Table 4-8: Top 20 Selling Drinks with Numbered Combinations for Zanzabar

\begin{tabular}{|l|l|l|}
\hline $\begin{array}{l}\text { Top 20 Selling } \\
\text { Drinks }\end{array}$ & Ingredients & $\begin{array}{l}\text { Number } \\
\text { Combinations }\end{array}$ \\
\hline Bloody Mary & Vodka and Zing Zang mix & \\
\hline Long Island Ice Tea & Dekuyper Bottle & \\
\hline Bourbon and Coke & Bourbon and Coke & \\
\hline Vodka Cranberry & Vodka and Cranberry & \\
\hline Screwdriver & Vodka and OJ & 4,7 \\
\hline Amaretto Sour & Amaretto and Sweet n Sour & $5,6,7,18$ \\
\hline Margarita & Tequila, Triple Sec, Sweet and Sour, and Lime Juice & 1,8 \\
\hline Sex on the Beach & Vodka, Peach Schnapps, OJ, Cranberry, and Pineapple & 5,9 \\
\hline Tequila Sunrise & Tequila, OJ, and Grenadine & 10,7 \\
\hline Whiskey Sour & Whiskey and Sweet n Sour & 1,11 \\
\hline White Russian & Vodka, Kahlua, and Cream & $12,13,14,7$ \\
\hline Apple Tini & Citrus Vodka, Apple Pucker, Melon Schnapps, and Sweet n Sour & $10,15,9$ \\
\hline Manhattan & Whiskey, Sweet Vermouth, and Grenadine & \\
\hline Tom Collins & Gin, Lemon Juice, Sugar, and Club soda & $12,18,17$ \\
\hline Cosmo & Citrus Vodka, Cranberry, Lime Juice, and Grand Marnier \\
\hline Fuzzy Navel & Peach Schnapps and OJ & \\
\hline Black Russian & Vodka and Kahlua & 1,11 \\
\hline Mai Tai & Rum, Malibu, OJ, Grenadine, and Pineapple & \\
\hline Sea Breeze & Vodka, Pineapple, and Grapefruit & \\
\hline Vodka Tonic & Vodka and Tonic & \\
\hline
\end{tabular}

10) List out the combinations which were successful (i.e. only adjacent moves were made) and which combinations were unsuccessful. (i.e. combinations with nonadjacent moves)

a. Combination 4-7 was successful.

b. Combination 5-6-7-18 was successful.

c. Combination 1-8 was successful.

d. Combination 5-9 was unsuccessful.

e. Combination 7-10 was unsuccessful.

f. Combination 1-11 was successful. 
g. Combination 12-13-14-7 was successful.

h. Combination 10-15-9 was successful.

i. Combination 12-18-17 was unsuccessful.

j. Combination 19-20-9 was successful.

The current speed rail for Zanzabar is shown in Figure 4-4. The figure shows how the bartender lays out the bottles initailly. As the day progresses the bartender will place additional bottles into the open spaces based on what people arriving to the bar are ordering. This means there are no adjacent moves and 17 nonadjacent moves.

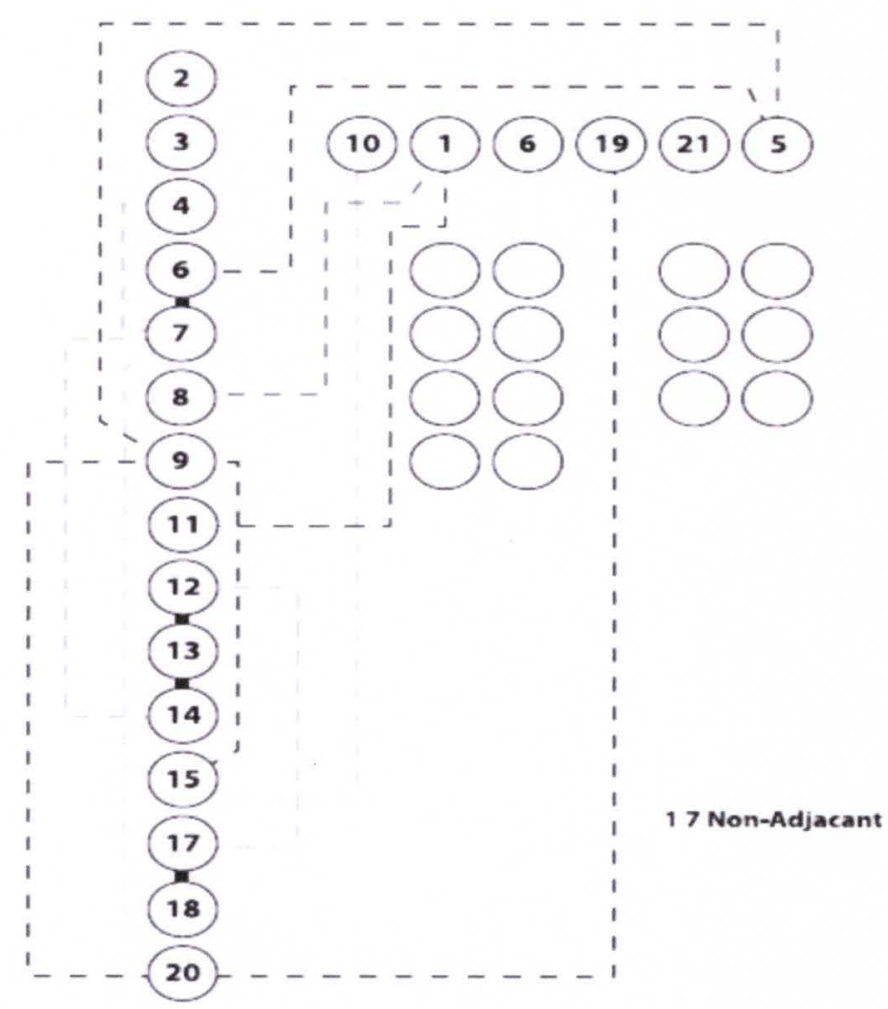

Figure 4-4: Current Speed Rail for Zanzabar 
In step seven of the heuristic the newly listed bottles are placed into the block

diagram; this can be seen in Figure 4-5. The bottles needed to mix the top twenty drinks are added to the diagram. Making those changes to the diagram show that the speed rail now has three adjacent moves and fourteen nonadjacent moves.

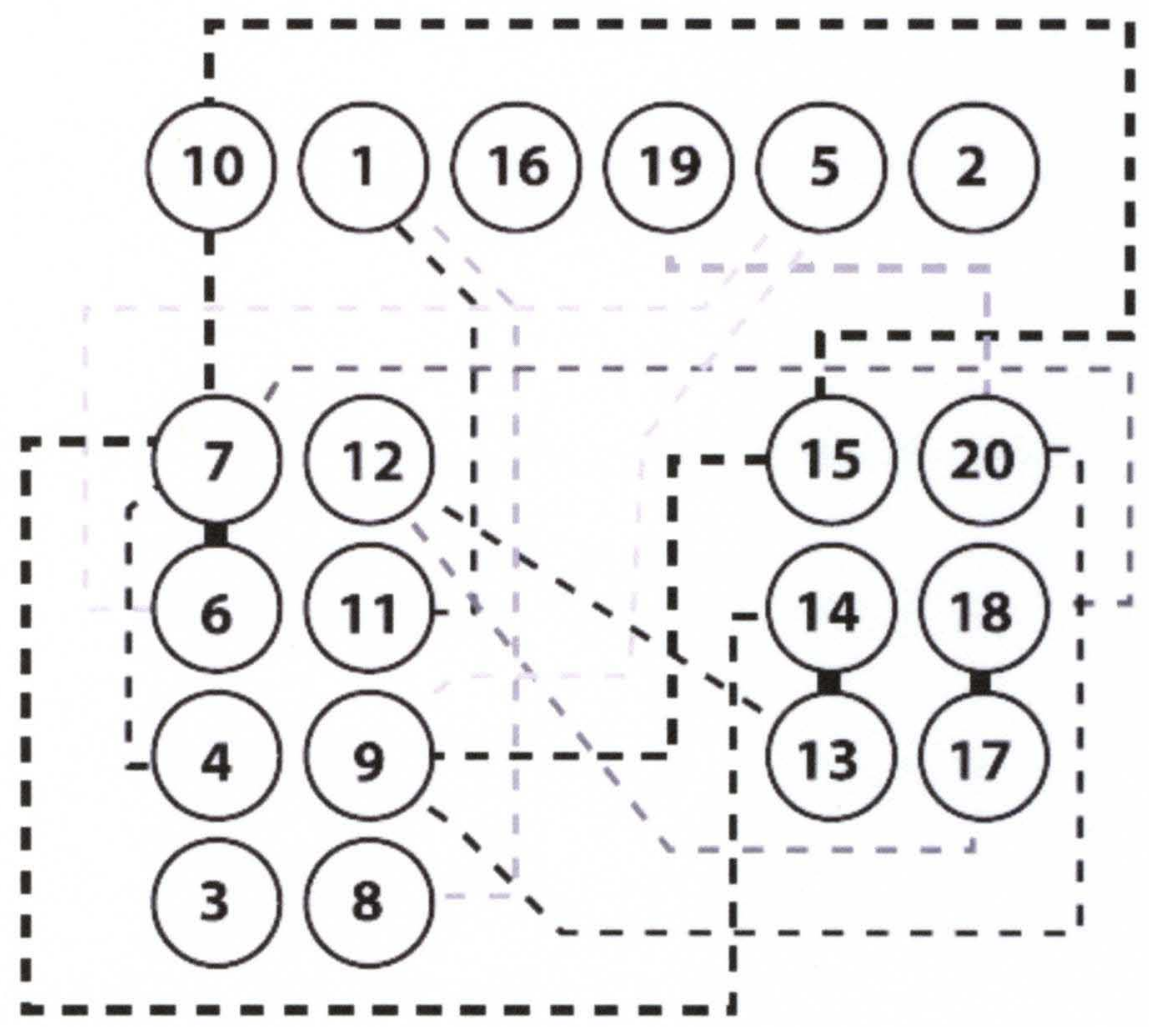

3 Adjacent

14 Non-Adjacant

Figure 4-5: Updated Speed Rail for Zanzabar

Below in Figure 4-6 shows the final completed block diagram for Zanzabar's bar using the heuristic method described. The resulting layout has fourteen adjacent moves and three nonadjacent moves. 


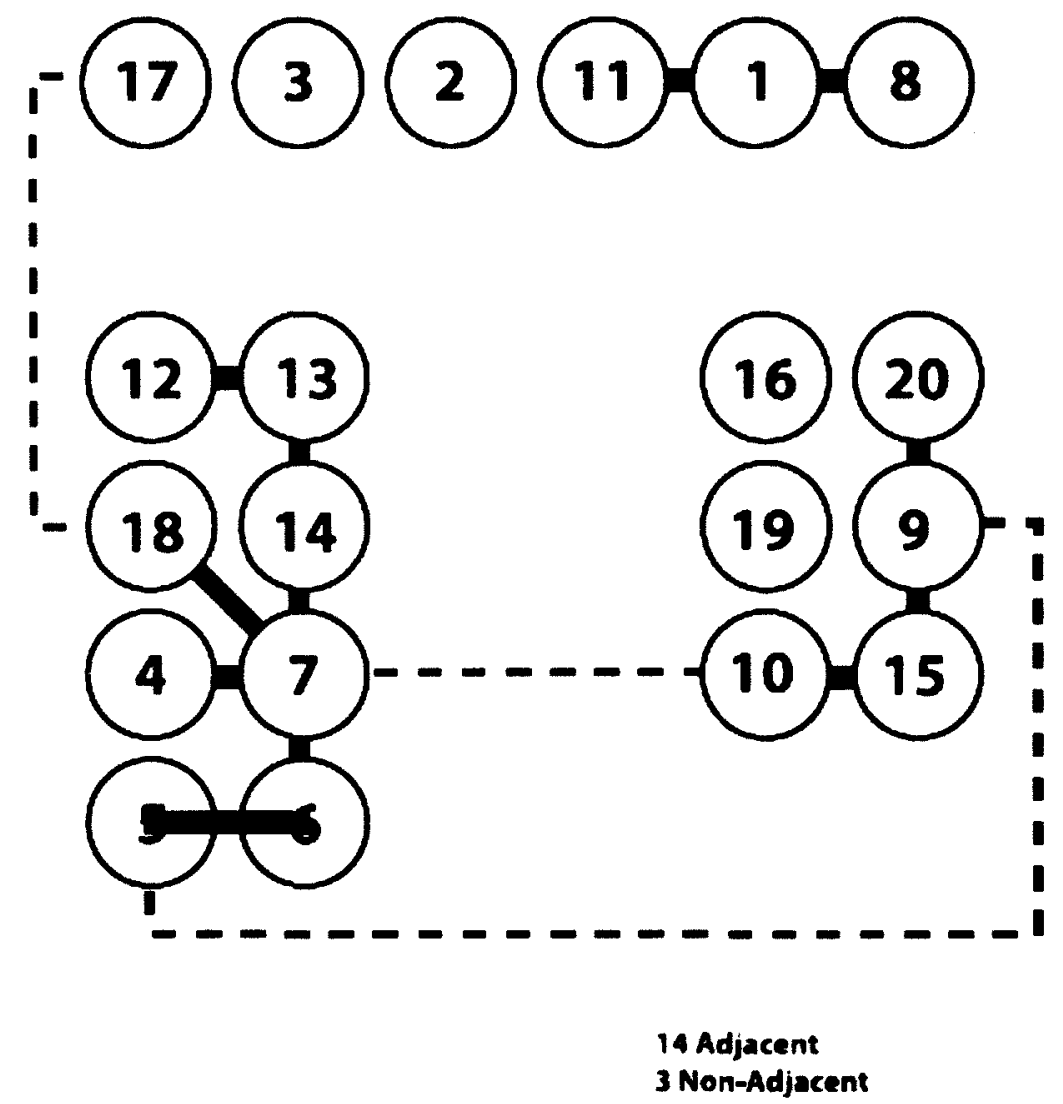

Figure 4-6: Computed Speed Rail for Zanzabar

\subsection{NAPA RIVER}

\subsubsection{BAR SUMMARY}

Napa River is an upscale bar and restaurant. It is located among many cute boutiques and other upscale places to eat. The clientele that Napa River has is more sophisticated and that transitions into the types of drinks that they make and carry. Napa River has an immense inventory of wines and many different brand name alcohols.

There are two separate bars in the restaurant; the main bar is inside and a smaller bar is outside and only opens when the weather is nice. The restaurant is very big and is very busy on the weekends and during happy hour every day. To combat the high number of 
customers ordering drinks Napa River has three bartenders at the main bar during their busiest hours. They have two different speed rails. One is smaller with only 12 spaces and holds their cheaper bottles of alcohol, known as the house brands, and is used to make quick and easy drinks. The second speed rail is very big and has space for 28 bottles most of which are different more expensive brands of the major alcohols, vodka, gin, scotch, whiskey, and so on. The research study saw many areas for improvement in these speed rails.

\subsubsection{NAPA RIVER INFORMATION}

The top 20 mixed drinks for Napa river are as follows: Vodka Tonic, Vodka Cranberry, Seven and Seven (Seagram's 7 and Sprite), Jack and Coke, Long Island Ice Tea (Vodka, Rum, Gin, Triple Sec, and Sweet n Sour), Margarita (Tequila, Triple Sec, Sweet and Sour, Lime Juice), Tom Collins (Gin, Lemon Juice, Sugar, Club soda), Sex on the Beach (Vodka, Peach Schnapps, OJ, Cranberry, Pineapple), Cosmo (Citrus Vodka, Cranberry, Grand Marnier, Lime Juice), Vodka Martini (Vodka and Dry Vermouth), Gin and Tonic, Manhattan (Whiskey, Sweet Vermouth, Grenadine), Scotch on the rocks, Gin Martini (Gin and Dry Vermouth), Baybreeze (Vodka, Cranberry, and Pineapple), Captain and Coke, Scotch and water, Screw Driver (Vodka and OJ), Whiskey Sour, and Rum and Coke.

There are 40 spots on the current speed rail but there are 36 spaces being used. The 36 bottles on the current speed rail are as follows: Tequila, Jameson (Scotch Whiskey), Rum, Gin, Vodka, Whiskey, Bourbon, Jim Beam, Maker’s Mark, Jack

Daniels, Sweet Vermouth, Dry Vermouth, Orange Vodka, Potato Vodka, 
Smirnoff(Vodka), Stoli (Vodka), Amaretto, Sour Apple, Pomegranate Liquor, Vodka, Tanqueray (Gin), Beefeater(Gin), Bombay (Gin), Absolut Vodka, Grey Goose (Vodka), Vodka, Crown Royal, Old Crowe (Bourbon), Seagram's 7, Bushmills (Scotch), Dewar's (Scotch), Triple Sec, Lime Juice, Sweet n Sour, Captain Morgan, and Rum.

There are only 18 different bottles needed to make the top 20 mixed drinks. In most cases generic alcohols would suffice but because of the upscale nature of the customers many different name brand alcohols are needed. The bottles needed are as follows: Vodka, Seagram's 7, Jack Daniels, Rum, Gin, Triple Sec, Sweet n Sour, Tequila, Lime Juice, Peach Schnapps, Citrus Vodka, Grand Marnier, Dry Vermouth, Whiskey, Sweet Vermouth, Grenadine, Scotch, and Captain Morgan. In this instance the extra spaces left in the speed rail will be saved for brand name alcohols such as Dewar's and Crown Royal.

\subsubsection{SPECIALIZED HEURISTIC AND BLOCK DIAGRAMS}

Each of the bars required a slightly altered version of the generic heuristic to maximize the number of adjacent moves, listed below is the specialized heuristic for Napa River.

1) Get a list of the top 20 mixed drinks sold and their ingredients. Using this information make a list of all the bottles needed to make these top 20 drinks. (list \#1 numbering the bottles $1,2, \ldots, \mathrm{n})$ 
Table 4-9: Alcohols Needed to Make the Top 20 Selling Drinks for Napa River

\begin{tabular}{|r|l|}
\hline $\begin{array}{l}\text { Bottle } \\
\text { Number }\end{array}$ & Alcohol \\
\hline 1 & Vodka \\
\hline 2 & Seagram's 7 \\
\hline 3 & Jack Daniels \\
\hline 4 & Rum \\
\hline 5 & Gin \\
\hline 6 & Triple Sec \\
\hline 7 & Sweet n Sour \\
\hline 8 & Tequila \\
\hline 9 & Lime Juice \\
\hline 10 & Peach Schnapps \\
\hline 11 & Citrus Vodka \\
\hline 12 & Grand Marnier \\
\hline 13 & Dry Vermouth \\
\hline 14 & Whiskey \\
\hline 15 & Sweet Vermouth \\
\hline 16 & Grenadine \\
\hline 17 & Dewar's (Scotch) \\
\hline 18 & Captain Morgan \\
\hline & \\
\hline
\end{tabular}

2) Write down the current speed rail layout.
a. 12 bottles on the single speed rail.
b. 24 bottles on a large speed rail.
c. Four bottles are off to the side.

3) Write down what bottles are currently on the speed rail. (list \#2) 
Table 4-10: Alcohols on the Current Speed Rail at Napa River

\begin{tabular}{|r|l|}
\hline $\begin{array}{l}\text { Bottle } \\
\text { Number }\end{array}$ & Alcohol \\
\hline 1 & Tequila \\
\hline 2 & Jameson \\
\hline 3 & Rum \\
\hline 4 & Gin \\
\hline 5 & Vodka \\
\hline 6 & Whiskey \\
\hline 7 & Bourbon \\
\hline 8 & Jim Beam \\
\hline 9 & Maker's Mark \\
\hline 10 & Jack Daniels \\
\hline 11 & Sweet Vermouth \\
\hline 12 & Dry Vermouth \\
\hline 13 & Orange Vodka \\
\hline 14 & Potato Vodka \\
\hline 15 & Smirnoff \\
\hline 16 & Stoli \\
\hline 17 & Amaretto \\
\hline 18 & Sour Apple \\
\hline 19 & Pomegranate Liquor \\
\hline 20 & Vodka \\
\hline 21 & Tanqueray \\
\hline 22 & Beefeater \\
\hline 23 & Bombay \\
\hline 24 & Absolut Vodka \\
\hline 25 & Grey Goose \\
\hline 26 & Vodka \\
\hline 27 & Crown Royal \\
\hline 28 & Old Crowe \\
\hline 29 & Seagram's 7 \\
\hline 30 & Bushmills \\
\hline 31 & Dewar's \\
\hline 32 & Triple Sec \\
\hline 33 & Lime Juice \\
\hline 34 & Sweet n Sour \\
\hline 35 & Captain Morgan \\
\hline 36 & Rum \\
\hline & \\
\hline & \\
\hline & \\
\hline &
\end{tabular}


4) Compare the bottles in list \#1 with the bottles in list \#2. Add the bottles that aren't in list \#1 but are in list \#2 to the end of list \#1. (This will be list \#3 numbering the bottles $1,2, \ldots, n, n+1, \ldots$ )

Table 4-11: All Alcohol Bottles Involved in Block Diagrams for Napa River

\begin{tabular}{|c|c|}
\hline $\begin{array}{l}\text { Bottle } \\
\text { Number }\end{array}$ & Alcohol \\
\hline 1 & Vodka \\
\hline 2 & Seagram's 7 \\
\hline 3 & Jack Daniels \\
\hline 4 & Rum \\
\hline 5 & Gin \\
\hline 6 & Triple Sec \\
\hline 7 & Sweet n Sour \\
\hline 8 & Tequila \\
\hline 9 & Lime Juice \\
\hline 10 & Peach Schnapps \\
\hline 11 & Citrus Vodka \\
\hline 12 & Grand Marnier \\
\hline 13 & Dry Vermouth \\
\hline 14 & Whiskey \\
\hline 15 & Sweet Vermouth \\
\hline 16 & Grenadine \\
\hline 17 & Dewar's (Scotch) \\
\hline 18 & Captain Morgan \\
\hline 19 & $\begin{array}{l}\text { Jameson (Scotch } \\
\text { Whiskey) }\end{array}$ \\
\hline 20 & Bourbon \\
\hline 21 & Jim Beam (Bourbon) \\
\hline 22 & Maker's Mark (Whisky) \\
\hline 23 & Orange Vodka \\
\hline 24 & Potato Vodka \\
\hline 25 & Smirnoff (Vodka) \\
\hline 26 & Stoli (Vodka) \\
\hline 27 & Amaretto \\
\hline 28 & Sour Apple \\
\hline 29 & Pomegranate Liquor \\
\hline
\end{tabular}




\begin{tabular}{|r|l|}
30 & Vodka \\
\hline 31 & Tanqueray (Gin) \\
\hline 32 & Beefeater (Gin) \\
\hline 33 & Bombay (Gin) \\
\hline 34 & Absolut Vodka \\
\hline 35 & Grey Goose (Vodka) \\
\hline 36 & Vodka \\
\hline 37 & Crown Royal (Whisky) \\
\hline 38 & Old Crowe (Bourbon) \\
\hline 39 & Bushmills (Scotch) \\
\hline 40 & Rum \\
\hline &
\end{tabular}

5) Draw a block diagram of the existing speed rail. All bottles that are needed but that aren't currently on the speed rail are automatically counted as a nonadjacent movement. (Use list \#3 to show where the different alcohols are located)

6) Compare and contrast list \#1 with list \#2. All of the bottles that were in list \#2 but not in list \#1 are taking up valued space and should be removed from the rail.

7) Place the bottles in the new block diagram according to their numbers from list $\# 1$. (i.e. $1,2, \ldots, n)$

a. There are 18 bottles needed to make up the top 20 mixed drinks.

8) (This is where the heuristic becomes specialized) Look at the list of drinks and separate out all the bottles that can stand alone or that have only a single connection. Total up how many bottles this is and try to place them on their own rail away from all the multiple combination drinks.

a. There are four bottles that stand alone and no bottles that share a single connection, this is four bottles total.

b. There are 40 total spaces on the speed rail and 18 bottles needed; the four bottles found can go anywhere because the speed rail is so large. 
9) Now determine which bottles are parts of multiple drink combinations and list the bottles with combinations over two.

a. Bottle 1 is in combinations with three other bottles: 4,10 , and 13 .

b. Bottle 5 is in combinations with three other bottles: 4,6 , and 13 .

c. Bottle 6 is in combinations with three other bottles: 5,7 , and 8 .

d. Bottle 7 is in combinations with three other bottles: 6, 9, and 14 .

Table 4-12: Top 20 Selling Drinks with Numbered Combinations for Napa River

\begin{tabular}{|l|l|l|}
\hline $\begin{array}{l}\text { Top 20 Selling } \\
\text { Drinks }\end{array}$ & Ingredients & $\begin{array}{l}\text { Number } \\
\text { Combinations }\end{array}$ \\
\hline Vodka Tonic & Vodka and Tonic & \\
\hline Vodka Cranberry & Vodka and Cranberry & \\
\hline Seven and Seven & Seagram's 7 and Sprite & \\
\hline Jack and Coke & Jack Daniels and Coke & $1,4,5,6,7$ \\
\hline $\begin{array}{l}\text { Long Island Ice } \\
\text { Tea }\end{array}$ & Vodka, Rum, Gin, Triple Sec, and Sweet n Sour \\
\hline Margarita & $\begin{array}{l}\text { Tequila, Triple Sec, Sweet and Sour, and Lime } \\
\text { Juice }\end{array}$ & $8,6,7,9$ \\
\hline Tom Collins & Gin, Lemon Juice, Sugar, and Club soda & \\
\hline Sex on the Beach & $\begin{array}{l}\text { Vodka, Peach Schnapps, OJ, Cranberry, and } \\
\text { Pineapple }\end{array}$ & 1,10 \\
\hline Cosmo & $\begin{array}{l}\text { Citrus Vodka, Cranberry, Grand Marnier, and Lime } \\
\text { Juice }\end{array}$ & $11,12,9$ \\
\hline Vodka Martini & Vodka and Dry Vermouth & 1,13 \\
\hline Gin and Tonic & Gin and Tonic & $14,15,16$ \\
\hline Manhattan & Whiskey, Sweet Vermouth, and Grenadine & \\
\hline $\begin{array}{l}\text { Scotch on the } \\
\text { rocks }\end{array}$ & Scotch & 5,13 \\
\hline Gin Martini & Gin and Dry Vermouth & \\
\hline Baybreeze & Vodka, Cranberry, and Pineapple & \\
\hline Captain and Coke & Captain and Coke & 14,7 \\
\hline Scotch and Water & Scotch and Water & \\
\hline Screw Driver & Vodka and OJ & \\
\hline Whiskey Sour & Whiskey and Sweet n Sour & \\
\hline Rum and Coke & Rum and Coke & \\
\hline & & \\
\hline
\end{tabular}


10) List out the combinations which were successful (i.e. only adjacent moves were made) and which combinations were unsuccessful. (i.e. combinations with nonadjacent moves)
a. Combination 1-4-5-6-7 was successful.
b. Combination 8-6-7-9 was successful.
c. Combination 1-10 was successful.
d. Combination 11-12-9 was successful.
e. Combination 1-13 was successful.
f. Combination 14-15-16 was successful.
g. Combination 5-13 was successful.
h. Combination 14-7 was successful.

The current speed rail for Napa River is shown in Figure 4-7. Looking at the figure it shows that there are are a few moves that require the bartender to to make nonadjactent moves. There are four adjacent moves and nine nonadjacent moves. 


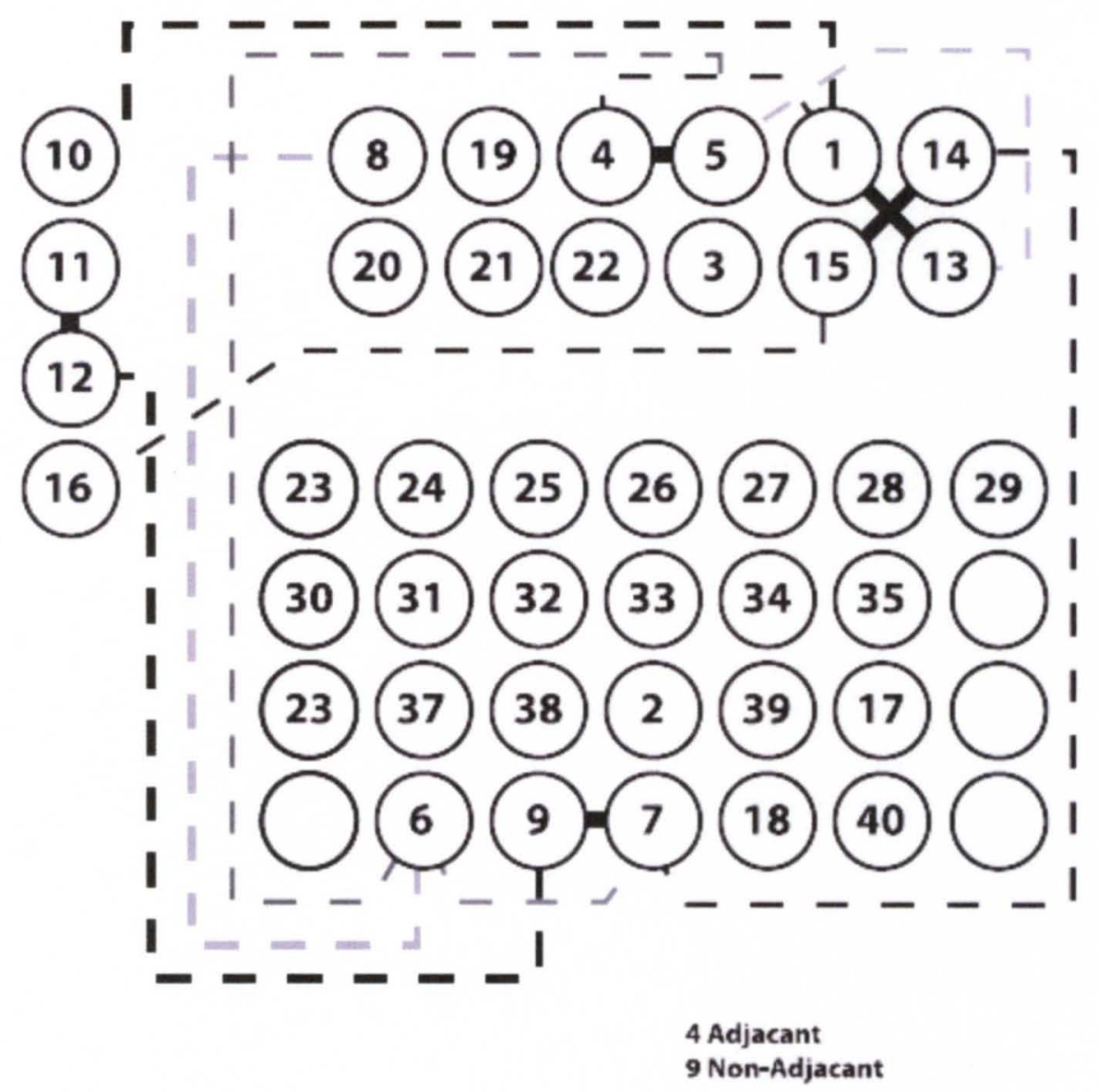

Figure 4-7: Speed Rail for Napa River

In step seven of the heuristic the newly listed bottles are placed into the block diagram; this can be seen in Figure 4-8. By just using the bottles needed to make the top 20 mixed drinks and adding those into the block diagram the group decreased the adjacent moves by one. This makes it so that there are three adjacent moves and 11 nonadjacent moves. 


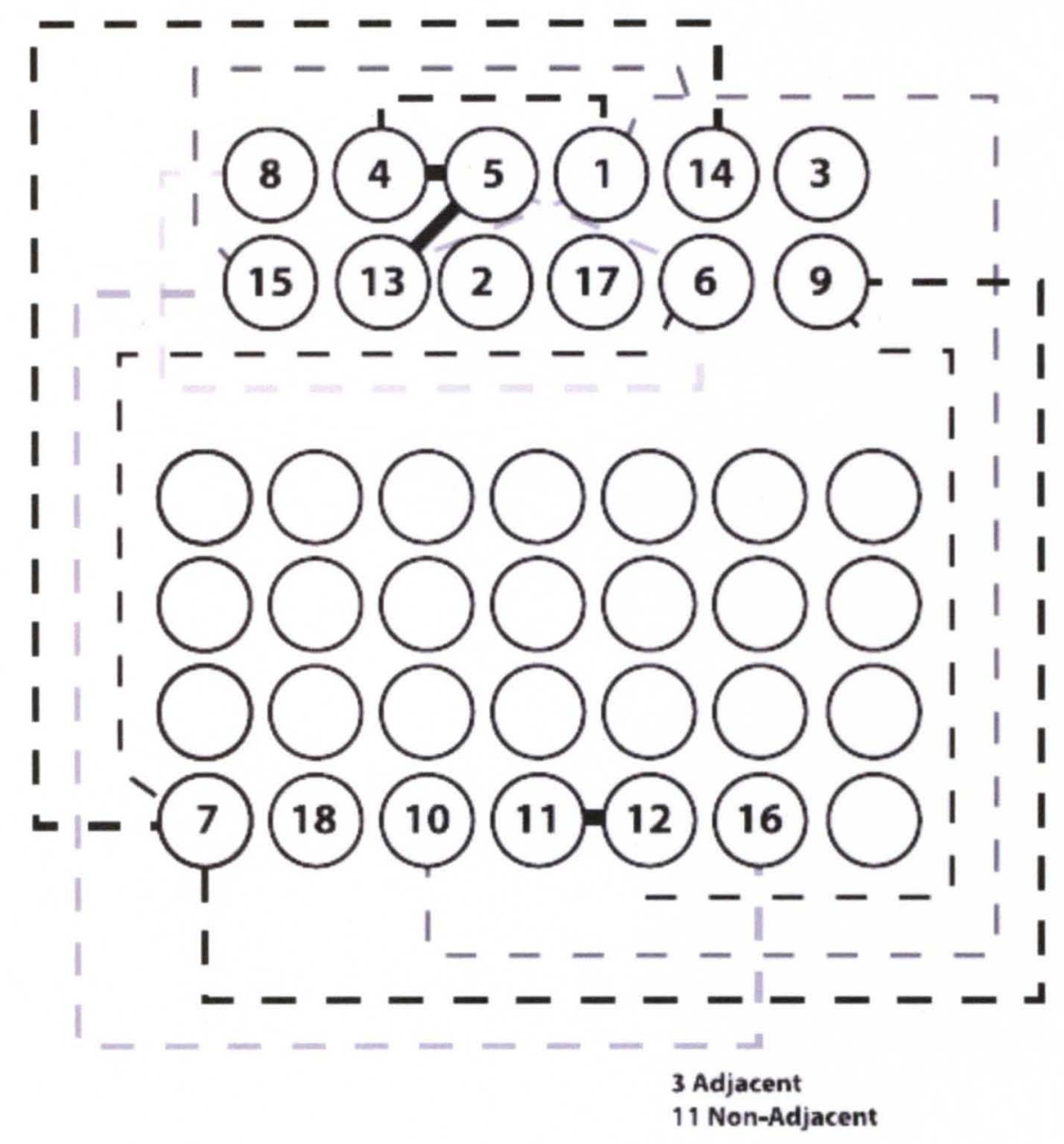

Figure 4-8: Updated Speed Rail for Napa River

Using the heuristic the group was able to compute an efficient speed rail. Figure 4-9 shows the final speed rail. This version has 14 adjacent moves and no nonadjacent moves. This is exactly what the study was hoping to find. 

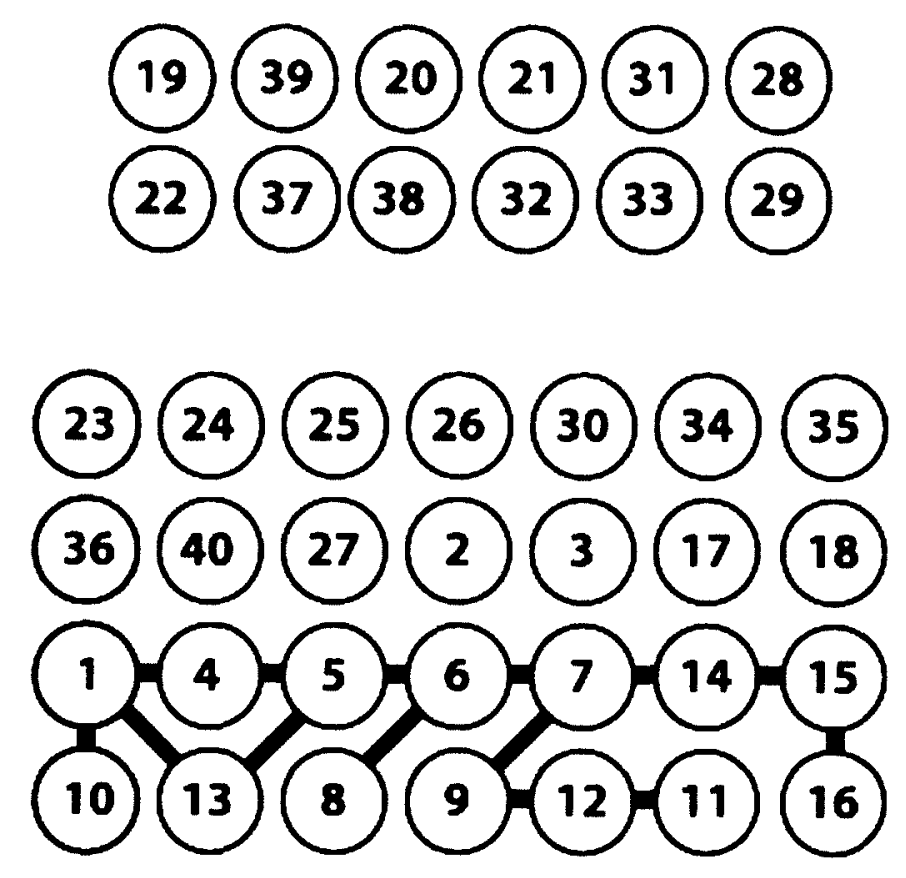

14 Adjacent Moves

Figure 4-9: Computed Speed Rail for Napa River 


\section{CHAPTER V}

\section{LINEAR PROGRAMMING}

\subsection{QUADRATIC ASSIGNMENT PROBLEM}

This study has used a heuristic based on block diagramming principles to try and maximize the efficiency of a speed rail and has computed new layouts for each of the three bars looked at. How can the study tell if these new layouts are good? By double checking the computed speed rails and the heuristic the study can show that block diagramming was effective in making the speed rails more efficient. The quadratic assignment problem will be used to double check the speed rail results.

The quadratic assignment problem uses n number of components and n number of places to assign each component to a particular location. In this study, there are $\mathrm{n}$ number of bottles needing to be placed in one of the $n$ number of spaces on the speed rail. The information needed for this problem is the number of bottles being used and the number of locations, the flow or relationships between the bottles, and the distance between the spaces on the speed rail. This is a binary nonlinear problem. The decision variable is $\mathrm{X}_{\mathrm{ij}}$ which equals one if bottle $\mathrm{i}$ is assigned to location $\mathrm{j}$ and zero otherwise. The parameters are $f_{i k}$ and $d_{j l}$. The flow between the bottles $i$ and $k$ is denoted by $f_{i k}$ and the distance between the locations $\mathrm{j}$ and $\mathrm{l}$ is denoted by $\mathrm{d}_{\mathrm{jl}}$. The formulation for this 
problem is shown in Figure 5-1. This problem can be evaluated using the software LINGO. (Hiller and Lieberman. 2005)

$$
\begin{gathered}
\text { MIN } \sum_{i} \sum_{i} \sum_{j} \sum_{i}\left(f_{i \dot{i}} d_{i j} X_{i j} X_{i i}\right) \\
\mathrm{ST} \quad \sum_{i} X_{i}=1 \quad \forall j \\
\sum_{j} X_{i}=1 \quad \forall i
\end{gathered}
$$

\section{Figure 5-1: Quadratic Assignment Problem Formulation}

\subsection{SMALL SCALE EXAMPLE}

To test and see if the general principles of the heuristic were good the study first evaluated a small scale example. The small scale example consisted of eight bottles on a speed rail that are meant to make three different drinks. The eight bottles are Amaretto, Sweet n Sour, Vodka, Rum, Gin, Triple Sec, Tequila, and Lime Juice (Table 5-1). The three drinks used are an Amaretto Sour, a Long Island Ice Tea, and a Margarita (Table 52). 
Table 5-1: Numbered Alcohols for Small Scale Example

\begin{tabular}{|r|l|}
\hline $\begin{array}{l}\text { Bottle } \\
\text { Number }\end{array}$ & Alcohol \\
\hline 1 & Amaretto \\
\hline 2 & $\begin{array}{l}\text { Sweet } \mathrm{n} \\
\text { Sour }\end{array}$ \\
\hline 3 & Vodka \\
\hline 4 & Rum \\
\hline 5 & Gin \\
\hline 6 & Triple Sec \\
\hline 7 & Tequila \\
\hline 8 & Lime Juice \\
\hline
\end{tabular}

Table 5-2: Numbered Drink Combinations for Small Scale Example

\begin{tabular}{|l|l|l|}
\hline Three Drinks & Ingredients & $\begin{array}{l}\text { Number } \\
\text { Combinations }\end{array}$ \\
\hline Amaretto Sour & Amaretto and Sweet $\mathbf{n}$ Sour & 1,2 \\
\hline $\begin{array}{l}\text { Long Island Ice } \\
\text { Tea }\end{array}$ & $\begin{array}{l}\text { Vodka, Rum, Gin, Triple Sec, and Sweet } \mathrm{n} \\
\text { Sour }\end{array}$ & $3,4,5,6,7$ \\
\hline Margarita & $\begin{array}{l}\text { Tequila, Triple Sec, Lime Juice and Sweet } \mathrm{n} \\
\text { Sour }\end{array}$ & $7,6,8,2$ \\
\hline
\end{tabular}

The speed rail itself is made up of two rows with four bottles on each row. The formulation and results in LINGO can be found in Appendix A. The graphical representation of the initial speed rail is shown in Figure 5-2 and the computed speed rail found using the quadratic assignment problem is shown in Figure 5-3. (Lindo Systems Inc.) 


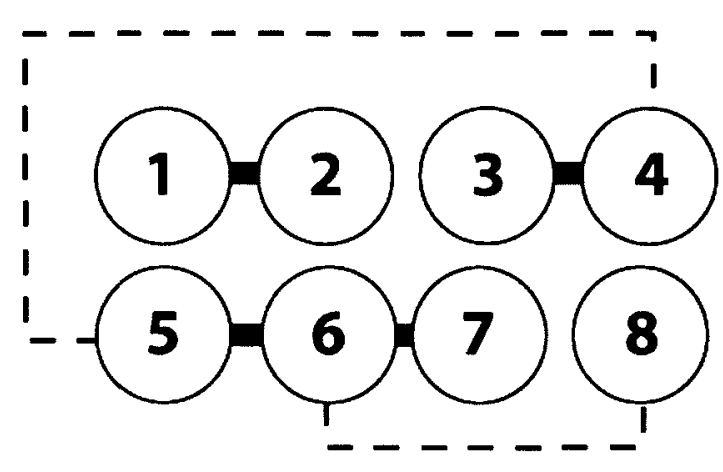

4 Adjocent

2 Nonadjacent

Figure 5-2: Initial Speed Rail for the Small Scale Example

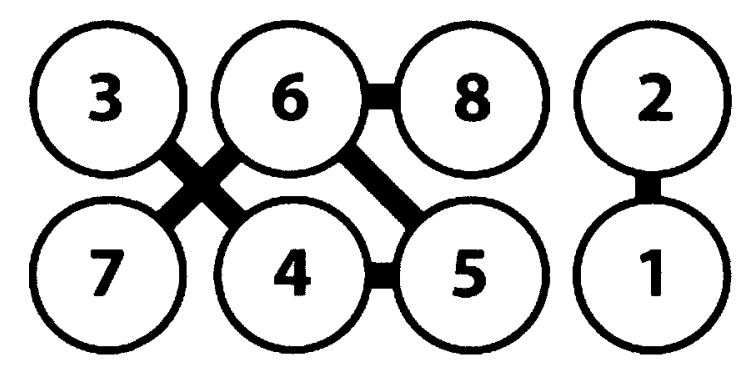

6 Adjacent

Figure 5-3: Computed Speed Rail for the Small Scale Example

LINGO and block diagramming computed the speed rail to have only adjacent movements. This shows that the principles of the heuristic are good. (Lindo Systems Inc.) 


\subsection{TWO KEYS EXAMPLE}

The study wanted to try a larger problem to see if the quadratic assignment problem and LINGO could come up with a solution in a reasonable time frame. Two Keys bar has exactly three times as many bottles as the small scale example. The research thought this to be an adequate larger scale example. Figure 5-4 shows the graphical results of what LINGO found to be the first feasible solution. (Lindo Systems Inc.)

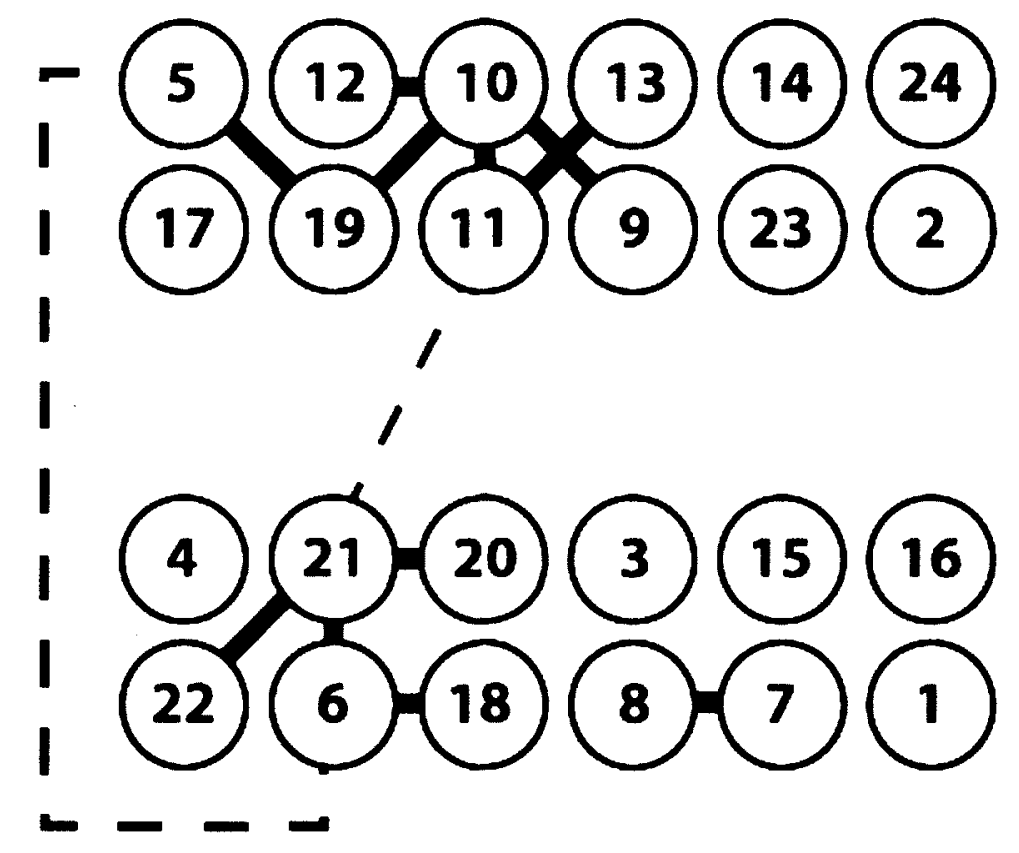

Figure 5-4: Computed Speed Rail for Two Keys Using Linear Programming

This graph proves that the heuristic found using block diagramming techniques is a good solution to the maximizing problem because the computed speed rail found using the heuristic is more efficient than the first feasible solution speed rail found using the 
quadratic assignment problem and LINGO. The computed speed rail found using LINGO had two nonadjacent movements but the computed speed rail using block diagramming had only one nonadjacent movement. The graph using block diagramming is shown again from a previous section as Figure 5-5. (Lindo Systems Inc.)
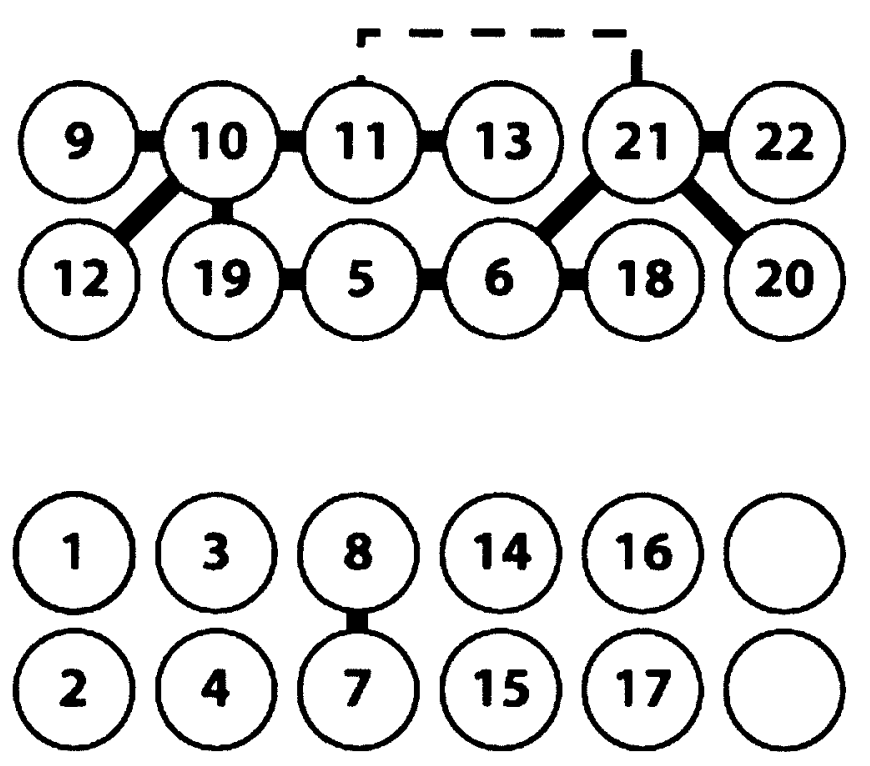

12 Adjacant

1 Nor-Adjacant

Figure 5-5: Computed Speed Rail for Two Keys Using Block Diagramming 


\section{CHAPTER VI}

\section{REAL WORLD EXAMPLE}

This study applied the results found from using block diagramming on Two Keys speed rail to form a real life example. The study kept track of the amount of time it took to make all top 20 selling mixed drinks using the current speed rail and then again using the new computed speed rail. By using some of this information, the study was able to give an example of how much time would be saved in one night and in one year using the new computed speed rail.

In the example there are eight tables, six of them have four customers sitting there and two of them have six customers sitting there. The research study assumed that each table would need a new round of drinks every 20 minutes on a regular night. On holidays such as Thanksgiving and Christmas, the group assumed that everyone sitting at a table would need a new drink every 15 minutes. The study focused on a six hour shift for the regular night. This means that on an average night there are 18 total orders, 36 drinks to be made at a time (six sets of four drinks and two sets of six drinks). On holidays a 10 hour shift was assumed and the study looked at 20 major holidays in which people like to drink. This means that there are 40 total orders on the holidays. The study wanted to keep everything simple and so an example was made for one round of drinks for each of the tables. This information was then used to find how much time would be saved on a 
regular night, on a holiday night, and over the span of an entire year. Because this example is so simple the results are probably a little bit off from the time that would actually be saved.

The study tracked how long it took to make each of the top 20 mixed drinks at Two Keys using the current speed rail and the new computed speed rail. Table 6-1 shows the times for both. The Real World Times represents the time it took to make a drink using the current speed rail and Improved Times is the time it took using the computed speed rail. 
Table 6-1: Times to Make Top Drinks Using Existing Speed Rail Vs. Computed Speed Rail

\begin{tabular}{|c|c|c|c|c|}
\hline Number & $\begin{array}{c}\text { Two Keys Top } 20 \text { Selling } \\
\text { Drinks } \\
\end{array}$ & $\begin{array}{c}\text { Current Speed Rail } \\
\text { Times } \\
\end{array}$ & $\begin{array}{c}\text { Improved Speed } \\
\text { Rail Times } \\
\end{array}$ & $\%$ Change \\
\hline 1 & Cherry Bomb & 11.59 & 8.55 & 26.23 \\
\hline 2 & Grape Bomb & 11.62 & 8.45 & 27.28 \\
\hline 3 & Captain and Coke & 8.69 & 8.3 & 4.49 \\
\hline 4 & Jack Daniels and Pepsi & 8.65 & 8.26 & 4.51 \\
\hline 5 & Rum and Pepsi & 8.74 & 8.35 & 4.46 \\
\hline 6 & Vodka and tonic & 8.6 & 8.4 & 2.33 \\
\hline 7 & BJ Shot & 10.1 & 7.39 & 26.83 \\
\hline 8 & Lemon Drop & 15.71 & 11.55 & 26.48 \\
\hline 9 & Margarita & 24.85 & 22.93 & 7.73 \\
\hline 10 & Parrot Bay and Pineapple & 15.52 & 12.72 & 18.04 \\
\hline 11 & Seven and Seven & 12.35 & 8.82 & 28.58 \\
\hline 12 & Jim Beam and Pepsi & 12.83 & 9.6 & 25.18 \\
\hline 13 & Vodka Cranberry & 12.83 & 10.64 & 17.07 \\
\hline 14 & $\begin{array}{c}\text { Raspberry Vodka and } \\
\text { Sprite } \\
\end{array}$ & 10.89 & 10.11 & 7.16 \\
\hline 15 & Vodka and Red Bull & 13.39 & 10.64 & 20.54 \\
\hline 16 & Vodka Martini & 26.45 & 17.75 & 32.89 \\
\hline 17 & Ice Pick & 14.14 & 10.87 & 23.13 \\
\hline 18 & Long Island & 26.72 & 22.01 & 17.63 \\
\hline 19 & Peach Martini & 26.31 & 18.64 & 29.16 \\
\hline 20 & Sex on the Beach & 17.14 & 12.44 & 27.42 \\
\hline
\end{tabular}

Table 6-2 looks at the studies example of one round of each drinks for each of the eight tables. Listed in the table are random drinks from the top 20 mixed drinks from Two Keys, the real world times and improved times it took to make each order, and the total difference in time. The difference in the two times is what the study focused on to see how much time could be saved. 
Table 6-2: Example Times for One Round of Drinks for the Eight Tables

\begin{tabular}{|c|c|c|c|c|c|c|c|}
\hline \multicolumn{8}{|c|}{ Tables } \\
\hline Orders & 1 & 2 & 3 & 4 & 5 & 6 & Totals \\
\hline 4 customers & $1,8,11,20$ & $2,7,10,19$ & $1,8,11,20$ & $5,8,15,16$ & $3,9,13,16$ & $2,7,10,19$ & \\
\hline $\begin{array}{l}\text { Real World } \\
\text { Times }\end{array}$ & 57 & 64 & 56.79 & 64.29 & 72.82 & 63.55 & 377.79 \\
\hline $\begin{array}{l}\text { Improved } \\
\text { Times }\end{array}$ & 41 & 47 & 41.36 & 48.29 & 59.62 & 47.2 & 285.05 \\
\hline \multicolumn{7}{|l|}{ Difference } & 92.76 \\
\hline 6 customers & $1,7,9,10,19,20$ & $2,5,8,13,16,20$ & & & & & \\
\hline $\begin{array}{l}\text { Real World } \\
\text { Times }\end{array}$ & 106 & 92 & & & & & 198 \\
\hline $\begin{array}{l}\text { Improved } \\
\text { Times }\end{array}$ & 83 & 69 & & & & & 151.85 \\
\hline \multicolumn{7}{|l|}{ Difference } & 46.15 \\
\hline
\end{tabular}

Using Table 6-2 it is easy to compute the time saved for one regular night, one holiday night, and one year. The total time saved by using the computed speed rail for one round of drinks in the example is the sum of the differences, $92.76+46.15$, or 138.91 seconds. This means that every time the bartender makes a drink they are saving roughly 2.32 minutes. Table $6-3$ shows all the calculations done to find the total time saved by using the computed speed rail. 
Table 6-3: Example Calculations for the Total Time Saved

\begin{tabular}{|c|c|}
\hline $\begin{array}{c}\text { Total time saved } \\
\text { for } \\
\text { one round of drinks }\end{array}$ & $92.76+46.15=2.32$ minutes \\
\hline $\begin{array}{c}\text { Total time saved } \\
\text { for } \\
\text { a regular night }\end{array}$ & $2.32 * 18=41.7$ minutes \\
\hline $\begin{array}{c}\text { Total time saved } \\
\text { for } \\
\text { a holiday night }\end{array}$ & $2.32 * 40=92.8$ minutes \\
\hline $\begin{array}{c}\text { Total time saved } \\
\text { for } \\
340 \text { regular nights }\end{array}$ & $41.7 * 340=9.85$ days \\
\hline $\begin{array}{c}\text { Total time saved } \\
\text { for } \\
20 \text { holiday nights }\end{array}$ & $92.8 * 20=1.28$ days \\
\hline $\begin{array}{c}\text { Total time saved } \\
\text { for } \\
\text { a year (360 days } \\
\text { open) }\end{array}$ & $9.85+1.28=11.13$ days \\
\hline
\end{tabular}

The study found that in every six hour shift on a regular night at Two Keys the bartender could possibly save 41.7 minutes by using the computed speed rail. The bartender could save 92.8 minutes on a holiday night by using the computed speed rail. To try and accurately estimate how much time would be saved throughout an entire year an elaborate example would need to be used. The study stuck with the idea that Two Keys would be fairly busy every single day and just multiplied the time saved for one regular night by 340 regular days that the bar would be open. This number is probably unrealistic. The same idea was applied to the holiday nights and the study assumed that there are 20 busy holidays throughout the year. This number is probably more accurate. Adding together the total time saved for 340 regular nights and 20 holiday nights the research study found that Two Keys could possibly save 11.13 days just by maximizing the efficiency of their speed rail. 


\section{CHAPTER VII}

\section{CONCLUSIONS, RECOMMENDATIONS, AND FUTURE RESEARCH}

\subsection{OVERVIEW}

The outcome of this study showed that by using block diagramming bars can make their current speed rails more efficient. The results at each of the three bars examined were all different in terms of just how efficient the study found their computed speed rails to be but the study did find a more efficient layout for each bar.

Each of the three bars examined have different needs based on peak times, space, and what type of bar they are. Two Keys is a small bar that has its peak times on the weekends. It needs an optimized speed rail to serve lots of customers as quickly as possible. This will help them to have a high turnover rate getting more customers in and out. The more customers you serve the more money you make in a small bar. At Two Keys the study was able to form a layout that has 12 adjacent movements and one nonadjacent movement.

Zanzabar is a medium size bar that experiences a daily peak during lunch as well as huge crowds on the weekends. During the lunch peak it is essential that customers are able to get in and out quickly due to their busy schedules. The weekend crowds are very steady so there are always customers waiting to be served. There is never any down time for a bartender. Customers need to be served quickly to make room for new customers. 
At Zanzabar the study was able to form a layout that has 14 adjacent movements and three nonadjacent movements.

Napa River Grill is a large restaurant that has its busiest hours during happy hour from five to seven and on the weekends. It is similar to Zanzabar in that respect. Customers must be served quickly so that the bartender can start making the next waiting order. At Napa River Grill the study was able to form a layout that has 14 adjacent movements and zero nonadjacent movements.

By applying a general heuristic to all three bars, all of the needs at each bar can be met to improve the time it takes to pour a drink and serve the customer. With minimal nonadjacent moves being made, bartenders can spend less time and energy making the drinks, allowing them to serve more customers, possibly increase sales, and possibly increase the customer's satisfaction. The general heuristic used seemed to result in more efficient speed rails but how could the study know if the results were good? A quadratic assignment problem from linear programming was used to judge whether or not the computed speed rails using block diagramming were good. The study looked at a small scale example and re-evaluated Two Keys bar and grill using this quadratic assignment problem. The results were similar to those found from using block diagramming which helps to show that the heuristic is a good way to find efficient speed rail layouts.

In each case, the research study focused on keeping the bottles needed for the top twenty mixed drinks close at hand in the speed rail so that the bartenders wouldn't waste time locating and fetching the bottles. By making sure all the needed bottles are on hand, bartenders can make many more drinks and can make them quicker than before. Time is 
money in the business world. This report shows how small and big businesses can make small changes that can save them time and therefore possibly save them money.

\subsection{RECOMMENDATIONS AND FUTURE RESEARCH}

This study focused on a unique idea that has almost no literature or additional information on the topic. More information on this topic needs to be published because there is hardly any information to reference regarding speed rails and their efficiency. As suggested, this study came up with a generalized heuristic using the principles of block diagramming to be able to maximize speed rail layouts from all different bars. Future studies regarding this topic could help bar owners and bartenders to maximize not only the speed rails but other aspects of their bar as well. It was suggested that time trials could be a way to further investigate the topic of this study.

This study was only able to cover how the alcohol bottles interact with one another on a speed rail; however there are a lot more interactions that take place behind a bar. For instance, some bars have ice machines, beer coolers, bar refrigerators, dishwashers, sinks, and storage for glassware all behind the bar. Future studies might be able to use block diagramming to explore many more of these connections than just one. This study might include how the placement of all the big equipment affects the time it takes the bartender to make a drink.

Engineers have so many different tools and programs at their disposal. This study was able to use two different engineering tools, block diagramming and linear programming, to try and maximize the efficiency of a speed rail. Being able to use the block diagrams formulated in this study in other areas such as simulation should be 
addressed in future research. This information would be useful to bar owners so that they could form better work schedules and plan on having entertainment on their slow nights to bring customers in.

This study was only able to focus on alcohol bottles and mixture bottles that could be placed on the speed rail. There is a lot more that can go into a drink such as soft drinks and juices which are normally found on the soda gun and in bar refrigerators. Future research studies should try and include the PFD approach mentioned in the literature review and add in all the other ingredients needed to make these top 20 selling mixed drinks. 


\section{REFERENCES}

Hiller, F. S., and G. J. Lieberman. 2005. Introduction to Operations Research, McGrawHill, New York, NY, 576-581.

http://www.bdti.com/articles/info_dspmt95blockdiagram.htm. 1995. Choosing BlockDiagram Tools for DSP Design.

http://findarticles.com/p/articles/mi_m3190/is_21_32/ai_50093121/.1998. Strategies for a successful bar layout and tips on how to avoid an inefficient design.

http://www.targetwoman.com/articles/bartending-job.html. 2010. Bartending Job.

Lindo Systems Inc. LINGO user's guide. Lindo Systems Inc., Chicago, IL. 2004.

McDonald, A. 2010. Make Your Restaurant Boom - Organizational Tips For a Successful Business. http://ezinearticles.com/?Make-Your-Restaurant-Boom---

Organizational-Tips- For-a-Successful- Business\&id=3616207

Russell, R. S., and B.W. Taylor III. 2009. Operations Management, Creating Value Along the Supply Chain, John Wiley \& Sons Inc, Hoboken, NJ, 260-262.

Shaeiwitz, J. A., R. C. Bailie, R. Turton, and W. B. Whiting. 2009. http://www.informit.com/articles/article.aspx?p=1314637

Wang, W., J. M. Loman, R. G. Arno, P. Vassiliou, E. R. Furlong, and D. Ogden. 2004. Reliability Block Diagram Simulation Techniques Applied to the IEEE Std. 493

Standard Network. IEEE TRANSACTIONS ON INDUSTRY APPLICATIONS, 40 (3), 887-895. http://www.weibull.com/knowledge/ieee493.pdf 
APPENDIX A: FORMULATION FOR SMALL SCALE EXAMPLE IN LINGO 


\section{Formulation for Small Scale Example in LINGO}

Model:

!Quadratic Assingment Problem;

Sets:

indexi /1..8/;

indexj $/ 1 . .8 /$;

indexk $/ 1 . .8 /$;

indexl /1..8/;

indexij(indexi,indexj): $x, f, d$;

indexikjl(indexi, indexk, indexj, indexl);

Endsets

Data:

$$
\begin{aligned}
& \text { !Parameter Values; } \\
& \mathrm{d}=000110011 \\
& 00010001 \\
& 10001000 \\
& 11001100 \\
& 00110011 \\
& 00010001 \\
& 10001000 \\
& 11001100 \text {; } \\
& \mathrm{f}=0 \begin{array}{lllllll}
0 & 0 & 0 & 0 & 0 & 0 & 0
\end{array} \\
& 00000000 \\
& 00010000 \\
& 00001000 \\
& 00000100 \\
& 000000011 \\
& 00000100 \\
& 00000000 \text {; }
\end{aligned}
$$

Enddata

!Objective Function;

Min = @ sum(indexikjl(i,k,j,l)|i\#ne\#k \#and\# j\#ne\#l:f(i,k)*d(j,l)*x(i,j)*x(k,l));

!Constraints;

@ for(indexj(j): @ sum(indexi(i):x(i,j))=1);

@for(indexi(i): @ sum(indexj(j):x(i,j))=1);

@ for(indexij(i,j): @BIN(x(i,j)));

end 
APPENDIX B: LINGO RESULTS FOR SMALL SCALE EXAMPLE 


\section{LINGO Results for Small Scale Example}

Local optimal solution found.

Objective value:

Objective bound:

Infeasibilities:

Extended solver steps:

Total solver iterations:
0.000000

0.000000

0.000000

2

69

$\begin{array}{lcc}\text { Variable } & \text { Value } & \text { Reduced Cost } \\ \mathrm{X}(1,1) & 0.000000 & 2.000000 \\ \mathrm{X}(1,2) & 0.000000 & 2.000000 \\ \mathrm{X}(1,3) & 0.000000 & 1.000000 \\ \mathrm{X}(1,4) & 0.000000 & 0.000000 \\ \mathrm{X}(1,5) & 0.000000 & 2.000000 \\ \mathrm{X}(1,6) & 0.000000 & 2.000000 \\ \mathrm{X}(1,7) & 0.000000 & 1.000000 \\ \mathrm{X}(1,8) & 1.000000 & 0.000000 \\ \mathrm{X}(2,1) & 0.000000 & 2.000000 \\ \mathrm{X}(2,2) & 0.000000 & 2.000000 \\ \mathrm{X}(2,3) & 0.000000 & 1.000000 \\ \mathrm{X}(2,4) & 1.000000 & 0.000000 \\ \mathrm{X}(2,5) & 0.000000 & 2.000000 \\ \mathrm{X}(2,6) & 0.000000 & 2.000000 \\ \mathrm{X}(2,7) & 0.000000 & 1.000000 \\ \mathrm{X}(2,8) & 0.000000 & 0.000000 \\ \mathrm{X}(3,1) & 1.000000 & 0.000000 \\ \mathrm{X}(3,2) & 0.000000 & 0.000000 \\ \mathrm{X}(3,3) & 0.000000 & 0.000000 \\ \mathrm{X}(3,4) & 0.000000 & 0.000000 \\ \mathrm{X}(3,5) & 0.000000 & 0.000000 \\ \mathrm{X}(3,6) & 0.000000 & 0.000000 \\ \mathrm{X}(3,7) & 0.000000 & 0.000000 \\ \mathrm{X}(3,8) & 0.000000 & 0.000000 \\ \mathrm{X}(4,1) & 0.000000 & 1.000000 \\ \mathrm{X}(4,2) & 0.000000 & 0.000000 \\ \mathrm{X}(4,3) & 0.000000 & 1.000000 \\ \mathrm{X}(4,4) & 0.000000 & 0.000000 \\ \mathrm{X}(4,5) & 0.000000 & 1.000000 \\ \mathrm{X}(4,6) & 1.000000 & 0.000000 \\ \mathrm{X}(4,7) & 0.000000 & 1.000000 \\ \mathrm{X}(4,8) & 0.000000 & 0.000000 \\ \mathrm{X}(5,1) & 0.000000 & 0.000000\end{array}$




\begin{tabular}{lll}
$\mathrm{X}(5,2)$ & 0.000000 & 0.000000 \\
$\mathrm{X}(5,3)$ & 0.000000 & 0.000000 \\
$\mathrm{X}(5,4)$ & 0.000000 & 1.000000 \\
$\mathrm{X}(5,5)$ & 0.000000 & 0.000000 \\
$\mathrm{X}(5,6)$ & 0.000000 & 0.000000 \\
$\mathrm{X}(5,7)$ & 1.000000 & 0.000000 \\
$\mathrm{X}(5,8)$ & 0.000000 & 1.000000 \\
$\mathrm{X}(6,1)$ & 0.000000 & 2.000000 \\
$\mathrm{X}(6,2)$ & 1.000000 & 0.000000 \\
$\mathrm{X}(6,3)$ & 0.000000 & 2.000000 \\
$\mathrm{X}(6,4)$ & 0.000000 & 1.000000 \\
$\mathrm{X}(6,5)$ & 0.000000 & 2.000000 \\
$\mathrm{X}(6,6)$ & 0.000000 & 0.000000 \\
$\mathrm{X}(6,7)$ & 0.000000 & 2.000000 \\
$\mathrm{X}(6,8)$ & 0.000000 & 1.000000 \\
$\mathrm{X}(7,1)$ & 0.000000 & 0.000000 \\
$\mathrm{X}(7,2)$ & 0.000000 & 0.000000 \\
$\mathrm{X}(7,3)$ & 0.000000 & 0.000000 \\
$\mathrm{X}(7,4)$ & 0.000000 & 1.000000 \\
$\mathrm{X}(7,5)$ & 1.000000 & 0.000000 \\
$\mathrm{X}(7,6)$ & 0.000000 & 0.000000 \\
$\mathrm{X}(7,7)$ & 0.000000 & 0.000000 \\
$\mathrm{X}(7,8)$ & 0.000000 & 1.000000 \\
$\mathrm{X}(8,1)$ & 0.000000 & 0.000000 \\
$\mathrm{X}(8,2)$ & 0.000000 & 0.000000 \\
$\mathrm{X}(8,3)$ & 1.000000 & 0.000000 \\
$\mathrm{X}(8,4)$ & 0.000000 & 0.000000 \\
$\mathrm{X}(8,5)$ & 0.000000 & 0.000000 \\
$\mathrm{X}(8,6)$ & 0.000000 & 0.000000 \\
$\mathrm{X}(8,7)$ & 0.000000 & 0.000000 \\
$\mathrm{X}(8,8)$ & 0.000000 & 0.000000 \\
$\mathrm{~F}(1,1)$ & 0.000000 & 0.000000 \\
$\mathrm{~F}(1,2)$ & 1.000000 & 0.000000 \\
$\mathrm{~F}(1,3)$ & 0.000000 & 0.000000 \\
$\mathrm{~F}(1,4)$ & 0.000000 & 0.000000 \\
$\mathrm{~F}(1,5)$ & 0.000000 & 0.000000 \\
$\mathrm{~F}(1,6)$ & 0.000000 & 0.000000 \\
$\mathrm{~F}(1,7)$ & 0.000000 & 0.000000 \\
$\mathrm{~F}(1,8)$ & 0.000000 & 0.000000 \\
$\mathrm{~F}(2,1)$ & 0.000000 & 0.000000 \\
$\mathrm{~F}(2,7)$ & 0.000000 & 0.000000 \\
$\mathrm{~F}(2,3)$ & 0.000000 & 0.000000 \\
$\mathrm{~F}(2,4)$ & 0.000000 & 0.000000 \\
& 0.000000 & 0.000000 \\
& 0.000000 & 0.000000 \\
\hline
\end{tabular}




$\begin{array}{lll}F(2,8) & 0.000000 & 0.000000 \\ F(3,1) & 0.000000 & 0.000000 \\ F(3,2) & 0.000000 & 0.000000 \\ F(3,3) & 0.000000 & 0.000000 \\ F(3,4) & 1.000000 & 0.000000 \\ F(3,5) & 0.000000 & 0.000000 \\ F(3,6) & 0.000000 & 0.000000 \\ F(3,7) & 0.000000 & 0.000000 \\ F(3,8) & 0.000000 & 0.000000 \\ F(4,1) & 0.000000 & 0.000000 \\ F(4,2) & 0.000000 & 0.000000 \\ F(4,3) & 0.000000 & 0.000000 \\ F(4,4) & 0.000000 & 0.000000 \\ F(4,5) & 1.000000 & 0.000000 \\ F(4,6) & 0.000000 & 0.000000 \\ F(4,7) & 0.000000 & 0.000000 \\ F(4,8) & 0.000000 & 0.000000 \\ F(5,1) & 0.000000 & 0.000000 \\ F(5,2) & 0.000000 & 0.000000 \\ F(5,3) & 0.000000 & 0.000000 \\ F(5,4) & 0.000000 & 0.000000 \\ F(5,5) & 0.000000 & 0.000000 \\ F(5,6) & 1.000000 & 0.000000 \\ F(5,7) & 0.000000 & 0.000000 \\ F(5,8) & 0.000000 & 0.000000 \\ F(6,1) & 0.000000 & 0.000000 \\ F(6,2) & 0.000000 & 0.000000 \\ F(6,3) & 0.000000 & 0.000000 \\ F(6,4) & 0.000000 & 0.000000 \\ F(6,5) & 0.000000 & 0.000000 \\ F(6,6) & 0.000000 & 0.000000 \\ F(6,7) & 1.000000 & 0.000000 \\ F(6,8) & 1.000000 & 0.000000 \\ F(7,1) & 0.000000 & 0.000000 \\ F(7,2) & 0.000000 & 0.000000 \\ F(7,3) & 0.000000 & 0.000000 \\ F(7,4) & 0.000000 & 0.000000 \\ F(7,5) & 0.000000 & 0.000000 \\ F(7,6) & 1.000000 & 0.000000 \\ F(7,7) & 0.000000 & 0.000000 \\ F(7,8) & 0.000000 & 0.000000 \\ F(8,1) & 0.000000 & 0.000000 \\ F(8,2) & 0.000000 & 0.000000 \\ F(8,3) & 0.000000 & 0.000000 \\ F(8,4) & 0.000000 & 0.000000 \\ F(8,5) & 0.000000 & 0.000000\end{array}$




$\begin{array}{lll}\mathrm{F}(8,6) & 0.000000 & 0.000000 \\ \mathrm{~F}(8,7) & 0.000000 & 0.000000 \\ \mathrm{~F}(8,8) & 0.000000 & 0.000000 \\ \mathrm{D}(1,1) & 0.000000 & 0.000000 \\ \mathrm{D}(1,2) & 0.000000 & 0.000000 \\ \mathrm{D}(1,3) & 1.000000 & 0.000000 \\ \mathrm{D}(1,4) & 1.000000 & 0.000000 \\ \mathrm{D}(1,5) & 0.000000 & 0.000000 \\ \mathrm{D}(1,6) & 0.000000 & 0.000000 \\ \mathrm{D}(1,7) & 1.000000 & 0.000000 \\ \mathrm{D}(1,8) & 1.000000 & 0.000000 \\ \mathrm{D}(2,1) & 0.000000 & 0.000000 \\ \mathrm{D}(2,2) & 0.000000 & 0.000000 \\ \mathrm{D}(2,3) & 0.000000 & 0.000000 \\ \mathrm{D}(2,4) & 1.000000 & 0.000000 \\ \mathrm{D}(2,5) & 0.000000 & 0.000000 \\ \mathrm{D}(2,6) & 0.000000 & 0.000000 \\ \mathrm{D}(2,7) & 0.000000 & 0.000000 \\ \mathrm{D}(2,8) & 1.000000 & 0.000000 \\ \mathrm{D}(3,1) & 1.000000 & 0.000000 \\ \mathrm{D}(3,2) & 0.000000 & 0.000000 \\ \mathrm{D}(3,3) & 0.000000 & 0.000000 \\ \mathrm{D}(3,4) & 0.000000 & 0.000000 \\ \mathrm{D}(3,5) & 1.000000 & 0.000000 \\ \mathrm{D}(3,6) & 0.000000 & 0.000000 \\ \mathrm{D}(3,7) & 0.000000 & 0.000000 \\ \mathrm{D}(3,8) & 0.000000 & 0.000000 \\ \mathrm{D}(4,1) & 1.000000 & 0.000000 \\ \mathrm{D}(4,2) & 1.000000 & 0.000000 \\ \mathrm{D}(4,3) & 0.000000 & 0.000000 \\ \mathrm{D}(4,4) & 0.000000 & 0.000000 \\ \mathrm{D}(4,5) & 1.000000 & 0.000000 \\ \mathrm{D}(4,6) & 1.000000 & 0.000000 \\ \mathrm{D}(4,7) & 0.000000 & 0.000000 \\ \mathrm{D}(4,8) & 0.000000 & 0.000000 \\ \mathrm{D}(5,1) & 0.000000 & 0.000000 \\ \mathrm{D}(5,2) & 0.000000 & 0.000000 \\ \mathrm{D}(5,3) & 1.000000 & 0.000000 \\ \mathrm{D}(5,4) & 1.000000 & 0.000000 \\ \mathrm{D}(5,5) & 0.000000 & 0.000000 \\ \mathrm{D}(5,6) & 0.000000 & 0.000000 \\ \mathrm{D}(5,7) & 1.000000 & 0.000000 \\ \mathrm{D}(5,8) & 1.000000 & 0.000000 \\ \mathrm{D}(6,1) & 0.000000 & 0.000000 \\ \mathrm{D}(6,2) & 0.000000 & 0.000000 \\ \mathrm{D}(6,3) & 0.000000 & 0.000000\end{array}$




\begin{tabular}{|c|c|c|}
\hline$D(6,4)$ & 1.000000 & 0.000000 \\
\hline$D(6,5)$ & 0.000000 & 0.000000 \\
\hline$D(6,6)$ & 0.000000 & 0.000000 \\
\hline $\mathrm{D}(6,7)$ & 0.000000 & 0.000000 \\
\hline$D(6,8)$ & 1.000000 & 0.000000 \\
\hline $\mathrm{D}(7,1)$ & 1.000000 & 0.000000 \\
\hline $\mathrm{D}(7,2)$ & 0.000000 & 0.000000 \\
\hline $\mathrm{D}(7,3)$ & 0.000000 & 0.000000 \\
\hline $\mathrm{D}(7,4)$ & 0.000000 & 0.000000 \\
\hline $\mathrm{D}(7,5)$ & 1.000000 & 0.000000 \\
\hline $\mathrm{D}(7,6)$ & 0.000000 & 0.000000 \\
\hline $\mathrm{D}(7,7)$ & 0.000000 & 0.000000 \\
\hline $\mathrm{D}(7,8)$ & 0.000000 & 0.000000 \\
\hline $\mathrm{D}(8,1)$ & 1.000000 & 0.000000 \\
\hline$D(8,2)$ & 1.000000 & 0.000000 \\
\hline $\mathrm{D}(8,3)$ & 0.000000 & 0.000000 \\
\hline $\mathrm{D}(8,4)$ & 0.000000 & 0.000000 \\
\hline $\mathrm{D}(8,5)$ & 1.000000 & 0.000000 \\
\hline$D(8,6)$ & 1.000000 & 0.000000 \\
\hline $\mathrm{D}(8,7)$ & 0.000000 & 0.000000 \\
\hline $\mathrm{D}(8,8)$ & 0.000000 & 0.000000 \\
\hline Row & Slack or Surplus & Dual Pric \\
\hline 1 & 0.000000 & -1.000000 \\
\hline 2 & 0.000000 & 0.000000 \\
\hline 3 & 0.000000 & 0.000000 \\
\hline 4 & 0.000000 & 0.000000 \\
\hline 5 & 0.000000 & -1.000000 \\
\hline 6 & 0.000000 & 0.000000 \\
\hline 7 & 0.000000 & 0.000000 \\
\hline 8 & 0.000000 & 0.000000 \\
\hline 9 & 0.000000 & -1.000000 \\
\hline 10 & 0.000000 & 1.000000 \\
\hline 11 & 0.000000 & 1.000000 \\
\hline 12 & 0.000000 & 0.000000 \\
\hline 13 & 0.000000 & 0.000000 \\
\hline 14 & 0.000000 & 0.000000 \\
\hline 15 & 0.000000 & 0.000000 \\
\hline 16 & 0.000000 & 0.000000 \\
\hline 17 & 0.000000 & 0.000000 \\
\hline
\end{tabular}




\section{APPENDIX C: FORMULATION FOR TWO KEYS EXAMPLE IN LINGO}


Formulation for Two Keys Example in LINGO

Model:

!Quadratic Assignment Problem;

Sets:

indexi /1..24/;

indexj /1..24/;

indexk /1..24/;

indexl /1..24/;

indexij(indexi,indexj):x,f,d;

indexikjl(indexi, indexk, indexj, indexl);

Endsets

Data:

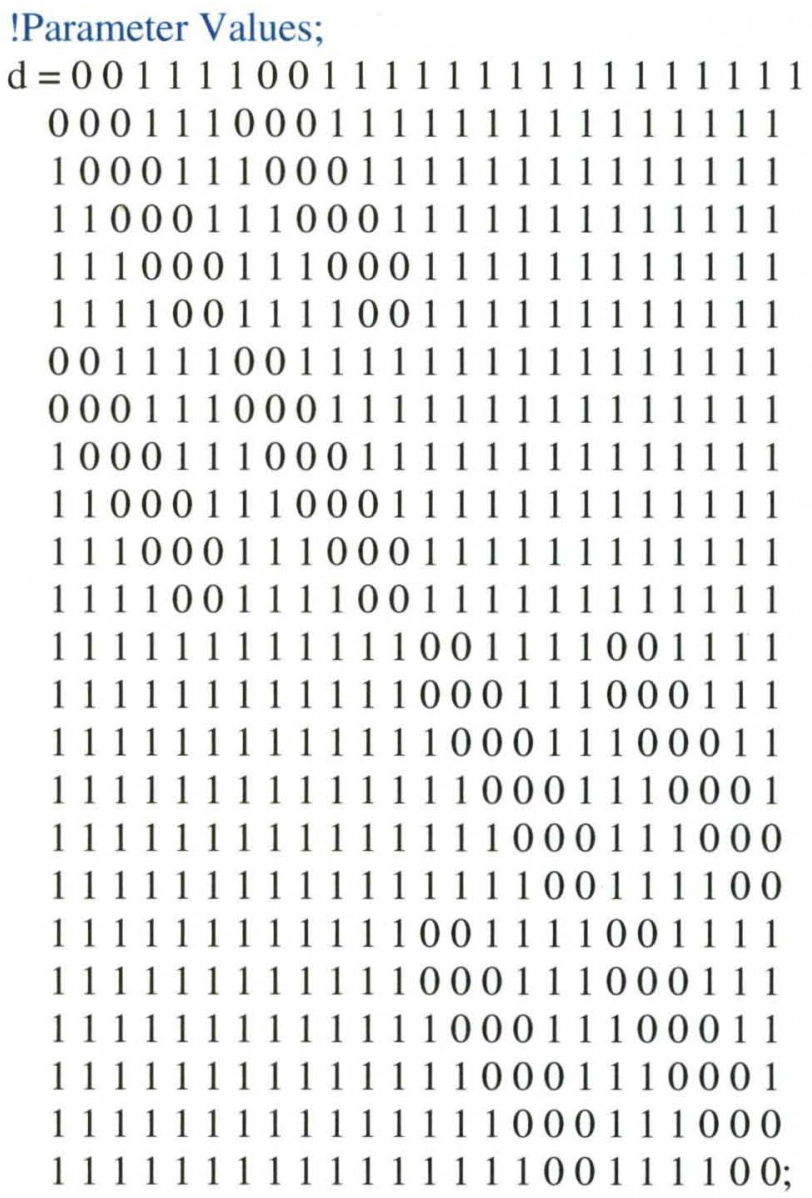




$$
\begin{aligned}
& \mathrm{f}=000000000000000000000000 \\
& 000000000000000000000000 \\
& 000000000000000000000000 \\
& 000000000000000000000000 \\
& 000001000000000000100000 \\
& 000010000000000001001000 \\
& 000000010000000000000000 \\
& 000000100000000000000000 \\
& 000000000100000000000000 \\
& 000000001011000000100000 \\
& 000000000100100000001000 \\
& 000000000100000000000000 \\
& 000000000010000000000000 \\
& 000000000000000000000000 \\
& 000000000000000000000000 \\
& 000000000000000000000000 \\
& 000000000000000000000000 \\
& 000001000000000000000000 \\
& 000010000100000000000000 \\
& 000000000000000000001000 \\
& 000001000010000000010100 \\
& 000000000000000000001000 \\
& 000000000000000000000000 \\
& 000000000000000000000000 \text {; }
\end{aligned}
$$

Enddata

!Objective Function;

Min = @ sum(indexikjl(i,k,j,l)|i\#ne\#k \#and\# j\#ne\#l:f(i,k)*d(j,l)*x(i,j)*x(k,l)); !Constraints;

@for(indexj(j): @ sum(indexi(i):x(i,j))=1);

@ for(indexi(i): @ sum(indexj(j):x(i,j))=1);

@ for(indexij(i,j): @BIN(x(i,j)));

end 


\section{APPENDIX D: LINGO RESULTS FOR TWO KEYS EXAMPLE}




\title{
LINGO Results for Two Keys Example
}

Local optimal solution found.

Objective value:

Objective bound:

Infeasibilities:

Extended solver steps:

Total solver iterations:

\author{
4.000000 \\ 4.000000 \\ 0.000000 \\ 76 \\ 8177
}

$\begin{array}{lcc}\text { Variable } & \text { Value } & \text { Reduced Cost } \\ \mathrm{X}(1,1) & 0.000000 & 0.000000 \\ \mathrm{X}(1,2) & 0.000000 & 0.000000 \\ \mathrm{X}(1,3) & 0.000000 & 0.000000 \\ \mathrm{X}(1,4) & 0.000000 & 0.000000 \\ \mathrm{X}(1,5) & 0.000000 & 0.000000 \\ \mathrm{X}(1,6) & 0.000000 & 0.000000 \\ \mathrm{X}(1,7) & 0.000000 & 0.000000 \\ \mathrm{X}(1,8) & 0.000000 & 0.000000 \\ \mathrm{X}(1,9) & 0.000000 & 0.000000 \\ \mathrm{X}(1,10) & 0.000000 & 0.000000 \\ \mathrm{X}(1,11) & 0.000000 & 0.000000 \\ \mathrm{X}(1,12) & 0.000000 & 0.000000 \\ \mathrm{X}(1,13) & 0.000000 & 0.000000 \\ \mathrm{X}(1,14) & 0.000000 & 0.000000 \\ \mathrm{X}(1,15) & 0.000000 & 0.000000 \\ \mathrm{X}(1,16) & 0.000000 & 0.000000 \\ \mathrm{X}(1,17) & 0.000000 & 0.000000 \\ \mathrm{X}(1,18) & 0.000000 & 0.000000 \\ \mathrm{X}(1,19) & 0.000000 & 0.000000 \\ \mathrm{X}(1,20) & 0.000000 & 0.000000 \\ \mathrm{X}(1,21) & 0.000000 & 0.000000 \\ \mathrm{X}(1,22) & 0.000000 & 0.000000 \\ \mathrm{X}(1,23) & 0.000000 & 0.000000 \\ \mathrm{X}(1,24) & 1.000000 & 0.000000 \\ \mathrm{X}(2,1) & 0.000000 & 0.000000 \\ \mathrm{X}(2,2) & 0.000000 & 0.000000 \\ \mathrm{X}(2,3) & 0.000000 & 0.000000 \\ \mathrm{X}(2,4) & 0.000000 & 0.000000 \\ \mathrm{X}(2,5) & 0.000000 & 0.000000 \\ \mathrm{X}(2,6) & 0.000000 & 0.000000 \\ \mathrm{X}(2,7) & 0.000000 & 0.000000 \\ \mathrm{X}(2,8) & 0.000000 & 0.000000 \\ \mathrm{X}(2,9) & 0.000000 & 0.000000 \\ & & \end{array}$




$\begin{array}{lcc}\mathrm{X}(2,10) & 0.000000 & 0.000000 \\ \mathrm{X}(2,11) & 0.000000 & 0.000000 \\ \mathrm{X}(2,12) & 1.000000 & 0.000000 \\ \mathrm{X}(2,13) & 0.000000 & 0.000000 \\ \mathrm{X}(2,14) & 0.000000 & 0.000000 \\ \mathrm{X}(2,15) & 0.000000 & 0.000000 \\ \mathrm{X}(2,16) & 0.000000 & 0.000000 \\ \mathrm{X}(2,17) & 0.000000 & 0.000000 \\ \mathrm{X}(2,18) & 0.000000 & 0.000000 \\ \mathrm{X}(2,19) & 0.000000 & 0.000000 \\ \mathrm{X}(2,20) & 0.000000 & 0.000000 \\ \mathrm{X}(2,21) & 0.000000 & 0.000000 \\ \mathrm{X}(2,22) & 0.000000 & 0.000000 \\ \mathrm{X}(2,23) & 0.000000 & 0.000000 \\ \mathrm{X}(2,24) & 0.000000 & 0.000000 \\ \mathrm{X}(3,1) & 0.000000 & 0.000000 \\ \mathrm{X}(3,2) & 0.000000 & 0.000000 \\ \mathrm{X}(3,3) & 0.000000 & 0.000000 \\ \mathrm{X}(3,4) & 0.000000 & 0.000000 \\ \mathrm{X}(3,5) & 0.000000 & 0.000000 \\ \mathrm{X}(3,6) & 0.000000 & 0.000000 \\ \mathrm{X}(3,7) & 0.000000 & 0.000000 \\ \mathrm{X}(3,8) & 0.000000 & 0.000000 \\ \mathrm{X}(3,9) & 0.000000 & 0.000000 \\ \mathrm{X}(3,10) & 0.000000 & 0.000000 \\ \mathrm{X}(3,11) & 0.000000 & 0.000000 \\ \mathrm{X}(3,12) & 0.000000 & 0.000000 \\ \mathrm{X}(3,13) & 0.000000 & 0.000000 \\ \mathrm{X}(3,14) & 0.000000 & 0.000000 \\ \mathrm{X}(3,15) & 0.000000 & 0.000000 \\ \mathrm{X}(3,16) & 1.000000 & 0.000000 \\ \mathrm{X}(3,17) & 0.000000 & 0.000000 \\ \mathrm{X}(3,18) & 0.000000 & 0.000000 \\ \mathrm{X}(3,19) & 0.000000 & 0.000000 \\ \mathrm{X}(3,20) & 0.000000 & 0.000000 \\ \mathrm{X}(3,21) & 0.000000 & 0.000000 \\ \mathrm{X}(3,22) & 0.000000 & 0.000000 \\ \mathrm{X}(3,23) & 0.000000 & 0.000000 \\ \mathrm{X}(3,24) & 0.000000 & 0.000000 \\ \mathrm{X}(4,1) & 0.000000 & 0.000000 \\ \mathrm{X}(4,2) & 0.000000 & 0.000000 \\ \mathrm{X}(4,3) & 0.000000 & 0.000000 \\ \mathrm{X}(4,4) & 0.000000 & 0.000000 \\ \mathrm{X}(4,5) & 0.000000 & 0.000000 \\ \mathrm{X}(4) & 0.000000 & 0.000000 \\ \mathrm{X}(3,60000 & 0.000000\end{array}$




$\begin{array}{lcc}\mathrm{X}(4,8) & 0.000000 & 0.000000 \\ \mathrm{X}(4,9) & 0.000000 & 0.000000 \\ \mathrm{X}(4,10) & 0.000000 & 0.000000 \\ \mathrm{X}(4,11) & 0.000000 & 0.000000 \\ \mathrm{X}(4,12) & 0.000000 & 0.000000 \\ \mathrm{X}(4,13) & 1.000000 & 0.000000 \\ \mathrm{X}(4,14) & 0.000000 & 0.000000 \\ \mathrm{X}(4,15) & 0.000000 & 0.000000 \\ \mathrm{X}(4,16) & 0.000000 & 0.000000 \\ \mathrm{X}(4,17) & 0.000000 & 0.000000 \\ \mathrm{X}(4,18) & 0.000000 & 0.000000 \\ \mathrm{X}(4,19) & 0.000000 & 0.000000 \\ \mathrm{X}(4,20) & 0.000000 & 0.000000 \\ \mathrm{X}(4,21) & 0.000000 & 0.000000 \\ \mathrm{X}(4,22) & 0.000000 & 0.000000 \\ \mathrm{X}(4,23) & 0.000000 & 0.000000 \\ \mathrm{X}(4,24) & 0.000000 & 0.000000 \\ \mathrm{X}(5,1) & 1.000000 & 0.000000 \\ \mathrm{X}(5,2) & 0.000000 & 0.000000 \\ \mathrm{X}(5,3) & 0.000000 & 0.000000 \\ \mathrm{X}(5,4) & 0.000000 & 2.000000 \\ \mathrm{X}(5,5) & 0.000000 & 2.000000 \\ \mathrm{X}(5,6) & 0.000000 & 2.000000 \\ \mathrm{X}(5,7) & 0.000000 & 0.000000 \\ \mathrm{X}(5,8) & 0.000000 & 0.000000 \\ \mathrm{X}(5,9) & 0.000000 & 0.000000 \\ \mathrm{X}(5,10) & 0.000000 & 2.000000 \\ \mathrm{X}(5,11) & 0.000000 & 2.000000 \\ \mathrm{X}(5,12) & 0.000000 & 2.000000 \\ \mathrm{X}(5,13) & 0.000000 & 0.000000 \\ \mathrm{X}(5,14) & 0.000000 & 0.000000 \\ \mathrm{X}(5,15) & 0.000000 & 0.000000 \\ \mathrm{X}(5,16) & 0.000000 & 2.000000 \\ \mathrm{X}(5,17) & 0.000000 & 2.000000 \\ \mathrm{X}(5,18) & 0.000000 & 2.000000 \\ \mathrm{X}(5,19) & 0.000000 & 0.000000 \\ \mathrm{X}(5,20) & 0.000000 & 0.000000 \\ \mathrm{X}(5,21) & 0.000000 & 0.000000 \\ \mathrm{X}(5,22) & 0.000000 & 2.000000 \\ \mathrm{X}(5,23) & 0.000000 & 2.000000 \\ \mathrm{X}(5,24) & 0.000000 & 2.000000 \\ \mathrm{X}(6,1) & 0.000000 & 2.000000 \\ \mathrm{X}(6,2) & 0.000000 & 2.000000 \\ \mathrm{X}, 3) & 0.000000 & 4.000000 \\ \mathrm{X}(5) & 0.000000 & 4.000000\end{array}$




\begin{tabular}{|c|c|c|}
\hline$X(6,6)$ & 0.000000 & 4.000000 \\
\hline$X(6,7)$ & 0.000000 & 2.000000 \\
\hline$X(6,8)$ & 0.000000 & 2.000000 \\
\hline$X(6,9)$ & 0.000000 & 4.000000 \\
\hline$X(6,10)$ & 0.000000 & 4.000000 \\
\hline$X(6,11)$ & 0.000000 & 4.000000 \\
\hline$X(6,12)$ & 0.000000 & 4.000000 \\
\hline$X(6,13)$ & 0.000000 & 2.000000 \\
\hline$X(6,14)$ & 0.000000 & 0.000000 \\
\hline$X(6,15)$ & 0.000000 & 0.000000 \\
\hline$X(6,16)$ & 0.000000 & 2.000000 \\
\hline$X(6,17)$ & 0.000000 & 4.000000 \\
\hline$X(6,18)$ & 0.000000 & 4.000000 \\
\hline$X(6,19)$ & 0.000000 & 2.000000 \\
\hline$X(6,20)$ & 1.000000 & 0.000000 \\
\hline$X(6,21)$ & 0.000000 & 0.000000 \\
\hline$X(6,22)$ & 0.000000 & 2.000000 \\
\hline$X(6,23)$ & 0.000000 & 4.000000 \\
\hline$X(6,24)$ & 0.000000 & 4.000000 \\
\hline$X(7,1)$ & 0.000000 & 2.000000 \\
\hline$X(7,2)$ & 0.000000 & 2.000000 \\
\hline$X(7,3)$ & 0.000000 & 2.000000 \\
\hline$X(7,4)$ & 0.000000 & 2.000000 \\
\hline$X(7,5)$ & 0.000000 & 2.000000 \\
\hline$X(7,6)$ & 0.000000 & 2.000000 \\
\hline$X(7,7)$ & 0.000000 & 2.000000 \\
\hline$X(7,8)$ & 0.000000 & 2.000000 \\
\hline$X(7,9)$ & 0.000000 & 2.000000 \\
\hline$X(7,10)$ & 0.000000 & 2.000000 \\
\hline$X(7,11)$ & 0.000000 & 2.000000 \\
\hline$X(7,12)$ & 0.000000 & 2.000000 \\
\hline$X(7,13)$ & 0.000000 & 2.000000 \\
\hline$X(7,14)$ & 0.000000 & 2.000000 \\
\hline$X(7,15)$ & 0.000000 & 0.000000 \\
\hline$X(7,16)$ & 0.000000 & 0.000000 \\
\hline$X(7,17)$ & 0.000000 & 0.000000 \\
\hline$X(7,18)$ & 0.000000 & 2.000000 \\
\hline$X(7,19)$ & 0.000000 & 2.000000 \\
\hline$X(7,20)$ & 0.000000 & 2.000000 \\
\hline$X(7,21)$ & 0.000000 & 0.000000 \\
\hline$X(7,22)$ & 0.000000 & 0.000000 \\
\hline$X(7,23)$ & 1.000000 & 0.000000 \\
\hline$X(7,24)$ & 0.000000 & 2.000000 \\
\hline$X(8,1)$ & 0.000000 & 2.000000 \\
\hline $\mathrm{X}(8,2)$ & 0.000000 & 2.000000 \\
\hline$X(8,3)$ & 0.000000 & 2.000000 \\
\hline
\end{tabular}




$\begin{array}{lcc}\mathrm{X}(8,4) & 0.000000 & 2.000000 \\ \mathrm{X}(8,5) & 0.000000 & 2.000000 \\ \mathrm{X}(8,6) & 0.000000 & 2.000000 \\ \mathrm{X}(8,7) & 0.000000 & 2.000000 \\ \mathrm{X}(8,8) & 0.000000 & 2.000000 \\ \mathrm{X}(8,9) & 0.000000 & 2.000000 \\ \mathrm{X}(8,10) & 0.000000 & 2.000000 \\ \mathrm{X}(8,11) & 0.000000 & 2.000000 \\ \mathrm{X}(8,12) & 0.000000 & 2.000000 \\ \mathrm{X}(8,13) & 0.000000 & 2.000000 \\ \mathrm{X}(8,14) & 0.000000 & 2.000000 \\ \mathrm{X}(8,15) & 0.000000 & 2.000000 \\ \mathrm{X}(8,16) & 0.000000 & 0.000000 \\ \mathrm{X}(8,17) & 0.000000 & 0.000000 \\ \mathrm{X}(8,18) & 0.000000 & 0.000000 \\ \mathrm{X}(8,19) & 0.000000 & 2.000000 \\ \mathrm{X}(8,20) & 0.000000 & 2.000000 \\ \mathrm{X}(8,21) & 0.000000 & 2.000000 \\ \mathrm{X}(8,22) & 1.000000 & 0.000000 \\ \mathrm{X}(8,23) & 0.000000 & 0.000000 \\ \mathrm{X}(8,24) & 0.000000 & 0.000000 \\ \mathrm{X}(9,1) & 0.000000 & 2.000000 \\ \mathrm{X}(9,2) & 0.000000 & 0.000000 \\ \mathrm{X}(9,3) & 0.000000 & 0.000000 \\ \mathrm{X}(9,4) & 0.000000 & 0.000000 \\ \mathrm{X}(9,5) & 0.000000 & 2.000000 \\ \mathrm{X}(9,6) & 0.000000 & 2.000000 \\ \mathrm{X}(9,7) & 0.000000 & 2.000000 \\ \mathrm{X}(9,8) & 0.000000 & 0.000000 \\ \mathrm{X}(9,9) & 0.000000 & 0.000000 \\ \mathrm{X}(9,10) & 1.000000 & 0.000000 \\ \mathrm{X}(9,11) & 0.000000 & 2.000000 \\ \mathrm{X}(9,24) & 0.000000 & 2.000000 \\ \mathrm{X}(9,12) & 0.000000 & 2.000000 \\ \mathrm{X}(9,13) & 0.000000 & 2.000000 \\ \mathrm{X}(9,14) & 0.000000 & 2.000000 \\ \mathrm{X}(9,15) & 0.000000 & 2.000000 \\ \mathrm{X}(9,16) & 0.000000 & 2.000000 \\ \mathrm{X}(9,17) & 0.000000 & 2.000000 \\ \mathrm{X}(9,18) & 0.000000 & 2.000000 \\ \mathrm{X}(9,19) & 0.000000 & 2.000000 \\ \mathrm{X}(9,20) & 0.000000 & 2.000000 \\ \mathrm{X}(9,21) & 0.000000 & 2.000000 \\ \mathrm{X}, 22) & 0.000000 & 2.000000 \\ \mathrm{X}, 1.0000000\end{array}$




\begin{tabular}{|c|c|c|}
\hline$X(10,2)$ & 0.000000 & 2.000000 \\
\hline$X(10,3)$ & 1.000000 & 0.000000 \\
\hline$X(10,4)$ & 0.000000 & 4.000000 \\
\hline$X(10,5)$ & 0.000000 & 6.000000 \\
\hline$X(10,6)$ & 0.000000 & 8.000000 \\
\hline$X(10,7)$ & 0.000000 & 4.000000 \\
\hline$X(10,8)$ & 0.000000 & 2.000000 \\
\hline$X(10,9)$ & 0.000000 & 0.000000 \\
\hline$X(10,10)$ & 0.000000 & 4.000000 \\
\hline$X(10,11)$ & 0.000000 & 6.000000 \\
\hline$X(10,12)$ & 0.000000 & 8.000000 \\
\hline$X(10,13)$ & 0.000000 & 8.000000 \\
\hline$X(10,14)$ & 0.000000 & 8.000000 \\
\hline$X(10,15)$ & 0.000000 & 8.000000 \\
\hline$X(10,16)$ & 0.000000 & 8.000000 \\
\hline$X(10,17)$ & 0.000000 & 8.000000 \\
\hline$X(10,18)$ & 0.000000 & 8.000000 \\
\hline$X(10,19)$ & 0.000000 & 8.000000 \\
\hline$X(10,20)$ & 0.000000 & 8.000000 \\
\hline$X(10,21)$ & 0.000000 & 8.000000 \\
\hline$X(10,22)$ & 0.000000 & 8.000000 \\
\hline$X(10,23)$ & 0.000000 & 8.000000 \\
\hline$X(10,24)$ & 0.000000 & 8.000000 \\
\hline$X(11,1)$ & 0.000000 & 4.000000 \\
\hline$X(11,2)$ & 0.000000 & 2.000000 \\
\hline$X(11,3)$ & 0.000000 & 0.000000 \\
\hline$X(11,4)$ & 0.000000 & 0.000000 \\
\hline$X(11,5)$ & 0.000000 & 2.000000 \\
\hline$X(11,6)$ & 0.000000 & 4.000000 \\
\hline$X(11,7)$ & 0.000000 & 4.000000 \\
\hline$X(11,8)$ & 0.000000 & 2.000000 \\
\hline$X(11,9)$ & 1.000000 & 0.000000 \\
\hline$X(11,10)$ & 0.000000 & 0.000000 \\
\hline$X(11,11)$ & 0.000000 & 2.000000 \\
\hline$X(11,12)$ & 0.000000 & 4.000000 \\
\hline$X(11,13)$ & 0.000000 & 2.000000 \\
\hline$X(11,14)$ & 0.000000 & 2.000000 \\
\hline$X(11,15)$ & 0.000000 & 2.000000 \\
\hline$X(11,16)$ & 0.000000 & 4.000000 \\
\hline$X(11,17)$ & 0.000000 & 4.000000 \\
\hline$X(11,18)$ & 0.000000 & 4.000000 \\
\hline$X(11,19)$ & 0.000000 & 2.000000 \\
\hline$X(11,20)$ & 0.000000 & 2.000000 \\
\hline$X(11,21)$ & 0.000000 & 2.000000 \\
\hline$X(11,22)$ & 0.000000 & 4.000000 \\
\hline$X(11,23)$ & 0.000000 & 4.000000 \\
\hline
\end{tabular}




$\begin{array}{lcc}\mathrm{X}(11,24) & 0.000000 & 4.000000 \\ \mathrm{X}(12,1) & 0.000000 & 2.000000 \\ \mathrm{X}(12,2) & 1.000000 & 0.000000 \\ \mathrm{X}(12,3) & 0.000000 & 0.000000 \\ \mathrm{X}(12,4) & 0.000000 & 0.000000 \\ \mathrm{X}(12,5) & 0.000000 & 2.000000 \\ \mathrm{X}(12,6) & 0.000000 & 2.000000 \\ \mathrm{X}(12,7) & 0.000000 & 2.000000 \\ \mathrm{X}(12,8) & 0.000000 & 0.000000 \\ \mathrm{X}(12,9) & 0.000000 & 0.000000 \\ \mathrm{X}(12,10) & 0.000000 & 0.000000 \\ \mathrm{X}(12,11) & 0.000000 & 2.000000 \\ \mathrm{X}(12,12) & 0.000000 & 2.000000 \\ \mathrm{X}(12,13) & 0.000000 & 2.000000 \\ \mathrm{X}(12,14) & 0.000000 & 2.000000 \\ \mathrm{X}(12,15) & 0.000000 & 2.000000 \\ \mathrm{X}(12,16) & 0.000000 & 2.000000 \\ \mathrm{X}(12,17) & 0.000000 & 2.000000 \\ \mathrm{X}(12,18) & 0.000000 & 2.000000 \\ \mathrm{X}(12,19) & 0.000000 & 2.000000 \\ \mathrm{X}(12,20) & 0.000000 & 2.000000 \\ \mathrm{X}(12,21) & 0.000000 & 2.000000 \\ \mathrm{X}(12,22) & 0.000000 & 2.000000 \\ \mathrm{X}(12,23) & 0.000000 & 2.000000 \\ \mathrm{X}(12,24) & 0.000000 & 2.000000 \\ \mathrm{X}(13,1) & 0.000000 & 2.000000 \\ \mathrm{X}(13,2) & 0.000000 & 0.000000 \\ \mathrm{X}(13,3) & 0.000000 & 0.000000 \\ \mathrm{X}(13,4) & 1.000000 & 0.000000 \\ \mathrm{X}(13,5) & 0.000000 & 2.000000 \\ \mathrm{X}(13,6) & 0.000000 & 2.000000 \\ \mathrm{X}(13,7) & 0.000000 & 2.000000 \\ \mathrm{X}(13,8) & 0.000000 & 0.000000 \\ \mathrm{X}(13,20) & 0.000000 & 2.000000 \\ \mathrm{X}(13,21) & 0.000000 & 2.000000 \\ \mathrm{X}(13,1) & 0.000000 & 0.000000 \\ \mathrm{X}(13,11) & 0.000000 & 0.000000 \\ \mathrm{X}(13,12) & 0.000000 & 2.000000 \\ \mathrm{X}(13,13) & 0.000000 & 2.000000 \\ \mathrm{X}(13,14) & 0.000000 & 2.000000 \\ \mathrm{X}(13,15) & 0.000000 & 2.000000 \\ \mathrm{X}(13,16) & 0.000000 & 2.000000 \\ \mathrm{X}(13,17) & 0.000000 & 2.000000 \\ \mathrm{X}(13,18) & 0.000000 & 2.000000 \\ \mathrm{X}, 19) & 0.000000 & \\ \mathrm{X}(13) & \end{array}$




$\begin{array}{ccc}\mathrm{X}(13,22) & 0.000000 & 2.000000 \\ \mathrm{X}(13,23) & 0.000000 & 2.000000 \\ \mathrm{X}(13,24) & 0.000000 & 2.000000 \\ \mathrm{X}(14,1) & 0.000000 & 0.000000 \\ \mathrm{X}(14,2) & 0.000000 & 0.000000 \\ \mathrm{X}(14,3) & 0.000000 & 0.000000 \\ \mathrm{X}(14,4) & 0.000000 & 0.000000 \\ \mathrm{X}(14,5) & 1.000000 & 0.000000 \\ \mathrm{X}(14,6) & 0.000000 & 0.000000 \\ \mathrm{X}(14,7) & 0.000000 & 0.000000 \\ \mathrm{X}(14,8) & 0.000000 & 0.000000 \\ \mathrm{X}(14,9) & 0.000000 & 0.000000 \\ \mathrm{X}(14,10) & 0.000000 & 0.000000 \\ \mathrm{X}(14,11) & 0.000000 & 0.000000 \\ \mathrm{X}(14,12) & 0.000000 & 0.000000 \\ \mathrm{X}(14,13) & 0.000000 & 0.000000 \\ \mathrm{X}(14,14) & 0.000000 & 0.000000 \\ \mathrm{X}(14,15) & 0.000000 & 0.000000 \\ \mathrm{X}(14,16) & 0.000000 & 0.000000 \\ \mathrm{X}(14,17) & 0.000000 & 0.000000 \\ \mathrm{X}(14,18) & 0.000000 & 0.000000 \\ \mathrm{X}(14,19) & 0.000000 & 0.000000 \\ \mathrm{X}(14,20) & 0.000000 & 0.000000 \\ \mathrm{X}(14,21) & 0.000000 & 0.000000 \\ \mathrm{X}(14,22) & 0.000000 & 0.000000 \\ \mathrm{X}(14,23) & 0.000000 & 0.000000 \\ \mathrm{X}(14,24) & 0.000000 & 0.000000 \\ \mathrm{X}(15,1) & 0.000000 & 0.000000 \\ \mathrm{X}(15,2) & 0.000000 & 0.000000 \\ \mathrm{X}(15,3) & 0.000000 & 0.000000 \\ \mathrm{X}(15,4) & 0.000000 & 0.000000 \\ \mathrm{X}(15,18) & 0.000000 & 0.000000 \\ \mathrm{X}(15,19) & 0.000000 & 0.000000 \\ \mathrm{X}(15,6) & 0.000000 & 0.000000 \\ \mathrm{X}(15,7) & 0.000000 & 0.000000 \\ \mathrm{X}(15,8) & 0.000000 & 0.000000 \\ \mathrm{X}(15,9) & 0.000000 & 0.000000 \\ \mathrm{X}(15,10) & 0.000000 & 0.000000 \\ \mathrm{X}(15,11) & 0.000000 & 0.000000 \\ \mathrm{X}(15,12) & 0.000000 & 0.000000 \\ \mathrm{X}(15,13) & 0.000000 & 0.000000 \\ \mathrm{X}(15,14) & 0.000000 & 0.000000 \\ \mathrm{X}(15,15) & 0.000000 & 0.000000 \\ \mathrm{X}(15,17) & 0.000000 & 0.000000 \\ & 1.000000 & 0.000000 \\ & 0.000000 & 0.000000 \\ & & \\ \mathrm{X}(15,18) & \end{array}$




\begin{tabular}{|c|c|c|}
\hline$X(15,20)$ & 0.000000 & 0.000000 \\
\hline$X(15,21)$ & 0.000000 & 0.000000 \\
\hline$X(15,22)$ & 0.000000 & 0.000000 \\
\hline$X(15,23)$ & 0.000000 & 0.000000 \\
\hline$X(15,24)$ & 0.000000 & 0.000000 \\
\hline$X(16,1)$ & 0.000000 & 0.000000 \\
\hline$X(16,2)$ & 0.000000 & 0.000000 \\
\hline$X(16,3)$ & 0.000000 & 0.000000 \\
\hline$X(16,4)$ & 0.000000 & 0.000000 \\
\hline$X(16,5)$ & 0.000000 & 0.000000 \\
\hline$X(16,6)$ & 0.000000 & 0.000000 \\
\hline$X(16,7)$ & 0.000000 & 0.000000 \\
\hline$X(16,8)$ & 0.000000 & 0.000000 \\
\hline$X(16,9)$ & 0.000000 & 0.000000 \\
\hline$X(16,10)$ & 0.000000 & 0.000000 \\
\hline$X(16,11)$ & 0.000000 & 0.000000 \\
\hline$X(16,12)$ & 0.000000 & 0.000000 \\
\hline$X(16,13)$ & 0.000000 & 0.000000 \\
\hline$X(16,14)$ & 0.000000 & 0.000000 \\
\hline$X(16,15)$ & 0.000000 & 0.000000 \\
\hline$X(16,16)$ & 0.000000 & 0.000000 \\
\hline$X(16,17)$ & 0.000000 & 0.000000 \\
\hline$X(16,18)$ & 1.000000 & 0.000000 \\
\hline$X(16,19)$ & 0.000000 & 0.000000 \\
\hline$X(16,20)$ & 0.000000 & 0.000000 \\
\hline$X(16,21)$ & 0.000000 & 0.000000 \\
\hline$X(16,22)$ & 0.000000 & 0.000000 \\
\hline$X(16,23)$ & 0.000000 & 0.000000 \\
\hline$X(16,24)$ & 0.000000 & 0.000000 \\
\hline$X(17,1)$ & 0.000000 & 0.000000 \\
\hline$X(17,2)$ & 0.000000 & 0.000000 \\
\hline$X(17,3)$ & 0.000000 & 0.000000 \\
\hline$X(17,4)$ & 0.000000 & 0.000000 \\
\hline$X(17,5)$ & 0.000000 & 0.000000 \\
\hline$X(17,6)$ & 0.000000 & 0.000000 \\
\hline$X(17,7)$ & 1.000000 & 0.000000 \\
\hline$X(17,8)$ & 0.000000 & 0.000000 \\
\hline$X(17,9)$ & 0.000000 & 0.000000 \\
\hline$X(17,10)$ & 0.000000 & 0.000000 \\
\hline$X(17,11)$ & 0.000000 & 0.000000 \\
\hline$X(17,12)$ & 0.000000 & 0.000000 \\
\hline$X(17,13)$ & 0.000000 & 0.000000 \\
\hline$X(17,14)$ & 0.000000 & 0.000000 \\
\hline$X(17,15)$ & 0.000000 & 0.000000 \\
\hline$X(17,16)$ & 0.000000 & 0.000000 \\
\hline$X(17,17)$ & 0.000000 & 0.000000 \\
\hline
\end{tabular}




$\begin{array}{lcc}\mathrm{X}(17,18) & 0.000000 & 0.000000 \\ \mathrm{X}(17,19) & 0.000000 & 0.000000 \\ \mathrm{X}(17,20) & 0.000000 & 0.000000 \\ \mathrm{X}(17,21) & 0.000000 & 0.000000 \\ \mathrm{X}(17,22) & 0.000000 & 0.000000 \\ \mathrm{X}(17,23) & 0.000000 & 0.000000 \\ \mathrm{X}(17,24) & 0.000000 & 0.000000 \\ \mathrm{X}(18,1) & 0.000000 & 2.000000 \\ \mathrm{X}(18,2) & 0.000000 & 2.000000 \\ \mathrm{X}(18,3) & 0.000000 & 2.000000 \\ \mathrm{X}(18,4) & 0.000000 & 2.000000 \\ \mathrm{X}(18,5) & 0.000000 & 2.000000 \\ \mathrm{X}(18,6) & 0.000000 & 2.000000 \\ \mathrm{X}(18,7) & 0.000000 & 2.000000 \\ \mathrm{X}(18,8) & 0.000000 & 2.000000 \\ \mathrm{X}(18,9) & 0.000000 & 2.000000 \\ \mathrm{X}(18,1)) & 0.000000 & 2.000000 \\ \mathrm{X}(18,11) & 0.000000 & 2.000000 \\ \mathrm{X}(18,12) & 0.000000 & 2.000000 \\ \mathrm{X}(18,13) & 0.000000 & 0.000000 \\ \mathrm{X}(18,14) & 0.000000 & 0.000000 \\ \mathrm{X}(18,15) & 0.000000 & 0.000000 \\ \mathrm{X}(18,16) & 0.000000 & 2.000000 \\ \mathrm{X}(18,17) & 0.000000 & 2.000000 \\ \mathrm{X}(18,18) & 0.000000 & 2.000000 \\ \mathrm{X}(18,19) & 0.000000 & 0.000000 \\ \mathrm{X}(18,20) & 0.000000 & 0.000000 \\ \mathrm{X}(18,21) & 1.000000 & 0.000000 \\ \mathrm{X}(18,22) & 0.000000 & 2.000000 \\ \mathrm{X}(18,23) & 0.000000 & 2.000000 \\ \mathrm{X}(18,24) & 0.000000 & 2.000000 \\ \mathrm{X}(19,1) & 0.000000 & 2.000000 \\ \mathrm{X}(19,2) & 0.000000 & 0.000000 \\ \mathrm{X}(19,14) & 0.000000 & 4.000000 \\ \mathrm{X}(19,3) & 0.000000 & 2.000000 \\ \mathrm{X}(19,4) & 0.000000 & 2.000000 \\ \mathrm{X}(19,5) & 0.000000 & 4.000000 \\ \mathrm{X}(19,6) & 0.000000 & 4.000000 \\ \mathrm{X}(19,7) & 0.000000 & 2.000000 \\ \mathrm{X}(19,8) & 1.000000 & 0.000000 \\ \mathrm{X}(19,9) & 0.000000 & 2.000000 \\ \mathrm{X}(19,10) & 0.000000 & 2.000000 \\ \mathrm{X}(19,11) & 0.000000 & 4.000000 \\ \mathrm{X}(19) & 0.000000 & 4.000000 \\ & 0.000000 & 4.000000\end{array}$




\begin{tabular}{|c|c|c|}
\hline$X(19,16)$ & 0.000000 & 4.000000 \\
\hline$X(19,17)$ & 0.000000 & 4.000000 \\
\hline$X(19,18)$ & 0.000000 & 4.00000 \\
\hline$X(19,19)$ & 0.000000 & 4.00000 \\
\hline$X(19,20)$ & 0.000000 & 4.00000 \\
\hline$X(19,21)$ & 0.000000 & 4.00000 \\
\hline$X(19,22)$ & 0.000000 & 4.00000 \\
\hline$X(19,23)$ & 0.000000 & 4.00000 \\
\hline$X(19,24)$ & 0.000000 & 4.00000 \\
\hline$X(20,1)$ & 0.000000 & 2.00000 \\
\hline$X(20,2)$ & 0.000000 & 2.000000 \\
\hline$X(20,3)$ & 0.000000 & 2.000000 \\
\hline$X(20,4)$ & 0.000000 & 2.00000 \\
\hline$X(20,5)$ & 0.000000 & 2.000000 \\
\hline$X(20,6)$ & 0.000000 & 2.000000 \\
\hline$X(20,7)$ & 0.000000 & 2.000000 \\
\hline$X(20,8)$ & 0.000000 & 2.000000 \\
\hline$X(20,9)$ & 0.000000 & 2.000000 \\
\hline$X(20,10)$ & 0.000000 & 2.00000 \\
\hline$X(20,11)$ & 0.000000 & 2.00000 \\
\hline$X(20,12)$ & 0.000000 & 2.00000 \\
\hline$X(20,13)$ & 0.000000 & 0.00000 \\
\hline$X(20,14)$ & 0.000000 & 0.00000 \\
\hline$X(20,15)$ & 1.000000 & 0.00000 \\
\hline$X(20,16)$ & 0.000000 & 2.00000 \\
\hline$X(20,17)$ & 0.000000 & 2.00000 \\
\hline$X(20,18)$ & 0.000000 & 2.00000 \\
\hline$X(20,19)$ & 0.000000 & 0.00000 \\
\hline$X(20,20)$ & 0.000000 & 0.00000 \\
\hline$X(20,21)$ & 0.000000 & 0.00000 \\
\hline$X(20,22)$ & 0.000000 & 2.00000 \\
\hline$X(20,23)$ & 0.000000 & 2.00000 \\
\hline$X(20,24)$ & 0.000000 & 2.00000 \\
\hline$X(21,1)$ & 0.000000 & 6.000000 \\
\hline$X(21,2)$ & 0.000000 & 4.00000 \\
\hline$X(21,3)$ & 0.000000 & 4.000000 \\
\hline$X(21,4)$ & 0.000000 & 4.000000 \\
\hline$X(21,5)$ & 0.000000 & 6.000000 \\
\hline$X(21,6)$ & 0.000000 & 6.000000 \\
\hline$X(21,7)$ & 0.000000 & 6.000000 \\
\hline$X(21,8)$ & 0.000000 & 4.000000 \\
\hline$X(21,9)$ & 0.000000 & 4.00000 \\
\hline$X(21,10)$ & 0.000000 & 4.00000 \\
\hline$X(21,11)$ & 0.000000 & 6.00000 \\
\hline$X(21,12)$ & 0.000000 & 6.00000 \\
\hline$X(21,13)$ & 0.000000 & 2.0000 \\
\hline
\end{tabular}




$\begin{array}{ccc}\mathrm{X}(21,14) & 1.000000 & 0.000000 \\ \mathrm{X}(21,15) & 0.000000 & 2.000000 \\ \mathrm{X}(21,16) & 0.000000 & 4.000000 \\ \mathrm{X}(21,17) & 0.000000 & 6.000000 \\ \mathrm{X}(21,18) & 0.000000 & 6.000000 \\ \mathrm{X}(21,19) & 0.000000 & 2.000000 \\ \mathrm{X}(21,20) & 0.000000 & 0.000000 \\ \mathrm{X}(21,21) & 0.000000 & 2.000000 \\ \mathrm{X}(21,22) & 0.000000 & 4.000000 \\ \mathrm{X}(21,23) & 0.000000 & 6.000000 \\ \mathrm{X}(21,24) & 0.000000 & 6.000000 \\ \mathrm{X}(22,1) & 0.000000 & 2.000000 \\ \mathrm{X}(22,2) & 0.000000 & 2.000000 \\ \mathrm{X}(22,3) & 0.000000 & 2.000000 \\ \mathrm{X}(22,4) & 0.000000 & 2.000000 \\ \mathrm{X}(22,5) & 0.000000 & 2.000000 \\ \mathrm{X}(22,6) & 0.000000 & 2.000000 \\ \mathrm{X}(22,7) & 0.000000 & 2.000000 \\ \mathrm{X}(22,8) & 0.000000 & 2.000000 \\ \mathrm{X}(22,9) & 0.000000 & 2.000000 \\ \mathrm{X}(22,10) & 0.000000 & 2.000000 \\ \mathrm{X}(22,11) & 0.000000 & 2.000000 \\ \mathrm{X}(22,12) & 0.000000 & 2.000000 \\ \mathrm{X}(22,13) & 0.000000 & 0.000000 \\ \mathrm{X}(22,14) & 0.000000 & 0.000000 \\ \mathrm{X}(22,15) & 0.000000 & 0.000000 \\ \mathrm{X}(22,16) & 0.000000 & 2.000000 \\ \mathrm{X}(22,17) & 0.000000 & 2.000000 \\ \mathrm{X}(22,18) & 0.000000 & 2.000000 \\ \mathrm{X}(22,19) & 1.000000 & 0.000000 \\ \mathrm{X}(22,20) & 0.000000 & 0.000000 \\ \mathrm{X}(22,21) & 0.000000 & 0.000000 \\ \mathrm{X}(22,22) & 0.000000 & 2.000000 \\ \mathrm{X}(22,23) & 0.000000 & 2.000000 \\ \mathrm{X}(22,24) & 0.000000 & 2.000000 \\ \mathrm{X}(23,1) & 0.000000 & 0.000000 \\ \mathrm{X}(23,2) & 0.000000 & 0.000000 \\ \mathrm{X}(23,3) & 0.000000 & 0.000000 \\ \mathrm{X}(23,4) & 0.000000 & 0.000000 \\ \mathrm{X}(23,5) & 0.000000 & 0.000000 \\ \mathrm{X}(23,6) & 0.000000 & 0.000000 \\ \mathrm{X}(23,7) & 0.000000 & 0.000000 \\ \mathrm{X}(23,8) & 0.000000 & 0.000000 \\ \mathrm{X}(23) & 0.000000 & 0.000000 \\ & 0.000000 & 0.000000 \\ & 1.000000 & 0.000000\end{array}$




$\begin{array}{ccc}\mathrm{X}(23,12) & 0.000000 & 0.000000 \\ \mathrm{X}(23,13) & 0.000000 & 0.000000 \\ \mathrm{X}(23,14) & 0.000000 & 0.000000 \\ \mathrm{X}(23,15) & 0.000000 & 0.000000 \\ \mathrm{X}(23,16) & 0.000000 & 0.000000 \\ \mathrm{X}(23,17) & 0.000000 & 0.000000 \\ \mathrm{X}(23,18) & 0.000000 & 0.000000 \\ \mathrm{X}(23,19) & 0.000000 & 0.000000 \\ \mathrm{X}(23,20) & 0.000000 & 0.000000 \\ \mathrm{X}(23,21) & 0.000000 & 0.000000 \\ \mathrm{X}(23,22) & 0.000000 & 0.000000 \\ \mathrm{X}(23,23) & 0.000000 & 0.000000 \\ \mathrm{X}(23,24) & 0.000000 & 0.000000 \\ \mathrm{X}(24,1) & 0.000000 & 0.000000 \\ \mathrm{X}(24,2) & 0.000000 & 0.000000 \\ \mathrm{X}(24,3) & 0.000000 & 0.000000 \\ \mathrm{X}(24,4) & 0.000000 & 0.000000 \\ \mathrm{X}(24,5) & 0.000000 & 0.000000 \\ \mathrm{X}(24,6) & 1.000000 & 0.000000 \\ \mathrm{X}(24,7) & 0.000000 & 0.000000 \\ \mathrm{X}(24,8) & 0.000000 & 0.000000 \\ \mathrm{X}(24,9) & 0.000000 & 0.000000 \\ \mathrm{X}(24,10) & 0.000000 & 0.000000 \\ \mathrm{X}(24,11) & 0.000000 & 0.000000 \\ \mathrm{X}(24,12) & 0.000000 & 0.000000 \\ \mathrm{X}(24,13) & 0.000000 & 0.000000 \\ \mathrm{X}(24,14) & 0.000000 & 0.000000 \\ \mathrm{X}(24,15) & 0.000000 & 0.000000 \\ \mathrm{X}(24,16) & 0.000000 & 0.000000 \\ \mathrm{X}(24,17) & 0.000000 & 0.000000 \\ \mathrm{X}(24,18) & 0.000000 & 0.000000 \\ \mathrm{X}(24,19) & 0.000000 & 0.000000 \\ \mathrm{X}(24,20) & 0.000000 & 0.000000 \\ \mathrm{X}(24,21) & 0.000000 & 0.000000 \\ \mathrm{X}(24,22) & 0.000000 & 0.000000 \\ \mathrm{X}(24,23) & 0.000000 & 0.000000 \\ \mathrm{X}(24,24) & 0.000000 & 0.000000\end{array}$




\title{
CIRRICULUM VITA
}

\author{
Ashley S. Riley \\ 1501 Bellamy Place - Apartment 1541-304 \\ Louisville, KY 40208 \\ (314) $503-5910$ \\ asrile02@louisville.edu
}

\section{OBJECTIVE}

Obtain an entry level position as an industrial engineer.

\section{EDUCATION}

University of Louisville, Louisville, KY

MS in Industrial Engineering

Expected Graduation, August 2010; GPA 3.575

Saint Mary-of-the-Woods College, Saint Mary-of-the-Woods, IN

BS in Mathematics

Graduated Summa Cum Laude, December 2008; GPA 3.8727

\section{PREVIOUS EMPLOYMENT}

Research Assistant/Teaching Assistant: University of Louisville, Louisville, KY - August 2009-Present

- Research journalism articles and other sources for professors

- Administer exams

Bartender: Two Keys, St. Louis, MO - January 2009-July 2009

- Prepared and served drink orders to customers

- Served food orders to customers

Weight Room Attendant: Saint Mary-of-the-Woods College, Saint Mary-of-the-Woods, IN - Sept. $2007-$ Dec. 2008

- Assisted students with equipment operation and exercise routines

- Supervised and cleaned facilities

\section{ACCOMPLISHMENTS \& INVOLVEMENT}

- Will have completed Master's Degree in three semesters through an accelerated program

- Received Graduate Teaching Assistant Scholarship to University of Louisville

- Participated in University of Louisville's Engineering Expo 2010 (Maximizing the Efficiency of a Speed Rail)

- Currently writing a Master's Thesis (Maximizing the Efficiency of a Speed Rail)

- Received Presidential Scholarship to Saint Mary-of-the-Woods College

- Presented in the 2008 Mathematics Conference at Notre Dame, IN (The Probability of Which Team Will Win the NCAA Basketball Tournament)

- Math Club President, Saint Mary-of-the-Woods - September 2007-May 2008 
- Student Representative for Mathematics Department, Saint Mary-of-the-Woods - September 2007-May 2008

- Member of Basketball Team, Saint Mary-of-the-Woods - September 2005-April 2007

- Graduated Valedictorian from Oakville Senior High School - May 2005

- South County Basketball Association, St. Louis, MO - September 2002-May 2005

- Wabash Valley Race for the Cure, Saint Mary-of-the-Woods, IN - October 2006

$\underline{\text { About Me }}$

During my undergraduate career I had the equivalent of two full time jobs, being a math major with a $3.8727 \mathrm{GPA}$ and being a member of the basketball team. I was successful in both of my endeavors and they taught me time management, responsibility, dedication, how to be a team player, how to achieve things as an individual, and how to balance whatever comes at me.

References available upon request 